\title{
The Hydrological Open Air Laboratory (HOAL) in Petzenkirchen: a hypothesis-driven observatory
}

\author{
G. Blöschl ${ }^{1,2}$, A. P. Blaschke ${ }^{1,2,8}$, M. Broer ${ }^{1}$, C. Bucher ${ }^{1,3}$, G. Carr ${ }^{1}$, X. Chen ${ }^{1}$, A. Eder ${ }^{1,4}$, M. Exner-Kittridge ${ }^{1,5}$, \\ A. Farnleitner ${ }^{1,6,8}$, A. Flores-Orozco ${ }^{7}$, P. Haas ${ }^{1,2}$, P. Hogan ${ }^{1}$, A. Kazemi Amiri ${ }^{1}$, M. Oismüller ${ }^{1}$, J. Parajka ${ }^{1,2}$,

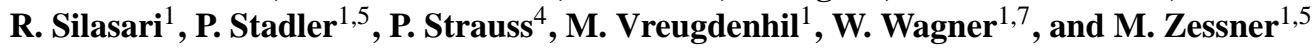 \\ ${ }^{1}$ Centre for Water Resource Systems, TU Wien, Karlsplatz 13, 1040 Vienna, Austria \\ ${ }^{2}$ Institute of Hydraulic Engineering and Water Resources Management, TU Wien, Karlsplatz 13/222, 1040 Vienna, Austria \\ ${ }^{3}$ Institute of Building Construction and Technology, TU Wien, Karlsplatz 13/206, 1040 Vienna, Austria \\ ${ }^{4}$ Institute for Land and Water Management Research, Federal Agency for Water Management, Pollnbergstraße 1, \\ 3252 Petzenkirchen, Austria \\ ${ }^{5}$ Institute for Water Quality, Resource and Waste Management, TU Wien, Karlsplatz 13/226, 1040 Vienna, Austria \\ ${ }^{6}$ Institute of Chemical Engineering, TU Wien, Gumpendorfer Straße 1a, 1060 Vienna, Austria \\ ${ }^{7}$ Department for Geodesy and Geoinformation, TU Wien, Gußhausstraße 25-29/120, 1040 Vienna, Austria \\ ${ }^{8}$ Interuniversity Cooperation Centre for Water \& Health, TU Wien, Vienna, Austria
}

Correspondence to: G. Blöschl (bloeschl@hydro.tuwien.ac.a)

Received: 26 June 2015 - Published in Hydrol. Earth Syst. Sci. Discuss.: 14 July 2015

Accepted: 14 December 2015 - Published: 18 January 2016

\begin{abstract}
Hydrological observatories bear a lot of resemblance to the more traditional research catchment concept, but tend to differ in providing more long-term facilities that transcend the lifetime of individual projects, are more strongly geared towards performing interdisciplinary research, and are often designed as networks to assist in performing collaborative science. This paper illustrates how the experimental and monitoring set-up of an observatory, the 66 ha Hydrological Open Air Laboratory (HOAL) in Petzenkirchen, Lower Austria, has been established in a way that allows meaningful hypothesis testing. The overarching science questions guided site selection, identification of dissertation topics and the base monitoring. The specific hypotheses guided the dedicated monitoring and sampling, individual experiments, and repeated experiments with controlled boundary conditions. The purpose of the HOAL is to advance the understanding of water-related flow and transport processes involving sediments, nutrients and microbes in small catchments. The HOAL catchment is ideally suited for this purpose, because it features a range of different runoff generation processes (surface runoff, springs, tile drains, wetlands), the nutrient inputs are known, and it is convenient from a logistic point of view as all instruments can be con-
\end{abstract}

nected to the power grid and a high-speed glassfibre local area network (LAN). The multitude of runoff generation mechanisms in the catchment provides a genuine laboratory where hypotheses of flow and transport can be tested, either by controlled experiments or by contrasting sub-regions of different characteristics. This diversity also ensures that the HOAL is representative of a range of catchments around the world, and the specific process findings from the HOAL are applicable to a variety of agricultural catchment settings. The HOAL is operated jointly by the Vienna University of Technology and the Federal Agency for Water Management and takes advantage of the Vienna Doctoral Programme on Water Resource Systems funded by the Austrian Science Funds. The paper presents the science strategy of the setup of the observatory, discusses the implementation of the HOAL, gives examples of the hypothesis testing and summarises the lessons learned. The paper concludes with an outlook on future developments. 


\section{Introduction}

Understanding water-related flow and transport processes in catchments and their interactions with other environmental processes across space scales and timescales forms essential research issues in the context of environmental technology, planning and management. From a water quantity perspective, understanding runoff generation mechanisms is very important for better estimating floods that may occur in small catchments, in particular if one is interested in extrapolating from small to large floods (Merz and Blöschl, 2008). Water yield under different management options as well as land-atmosphere feedbacks are particularly relevant when addressing issues related to climate change. From chemical and sediment perspectives, understanding the relevant mechanisms is important in the context of land management practices that aim at reducing sediment production (e.g. Yeshaneh et al., 2015), and for water resource management where the interest resides in understanding the fate of nutrients and designing relevant management practices (Schilling et al., 2005; Zessner et al., 2005; Strauss and Klaghofer, 2006; Kovacs et al., 2012). From a human-health-related perspective, characterising microbial faecal hazards in water and identifying contamination sources contribute to more reliable hazard characterisation and risk estimation in the context of water safety management, for example by allowing target-oriented protection measures in the catchment and delineating effective and site-specific protection zones (Reischer et al., 2011; Farnleitner et al., 2011). While these research issues are relevant individually, they are also closely connected to each other through process interactions. Integrated research into these processes is therefore needed to shed light on the interactions and fully explore the causal relationships of the catchment system.

Experimental research addressing these issues differs from experiments in many other fields of science in at least two ways. First, the processes related to water flow in the landscape are strongly controlled by the forcing of the weather. It is therefore difficult, if not impossible, to conduct controlled experiments where one varies the boundary conditions in a prescribed way. As a consequence, the processes associated with water flow are intrinsically non-repeatable and require particular care when hypothesis testing (Blöschl et al., 2014). Second, the processes occur at the catchment scale (where much of the interesting process interactions occur) and may not be present at the small laboratory scale. As a result, the experimental set-up must be designed at the catchment scale which, again, involves a number of scientific and logistic challenges.

Experimental catchments have a long tradition in hydrology. Some corner stones include the Coweeta hydrologic laboratory (Southern Appalachians) in the early 1930s where the focus was on forest management practices (Swank and Crossley, 1988; Elliott and Vose, 2011), the Plynlimon catchment (Wales) in the late 1960s where pollution was the main interest (Kirby et al., 1991; Robinson et al., 2013), the Weiherbach (Germany) and Löhnersbach (Austria) catchments in the 1990s where a broader, interdisciplinary approach was taken (Plate and Zehe, 2008; Zehe et al., 2001; Kirnbauer et al., 2005); and the Tarrawarra catchment (Australia) in the 1990s where the focus was specifically on spatial process patterns (Western et al., 1998, 1999, 2001). An overview of some of the European experimental catchments is given in Schumann et al. (2010) and Holko et al. (2015).

More recently, the concept of environmental observatories has been developed and implemented. Examples are the Critical Zone Observatories (CZO) in the US where the starting point was geochemical processes (e.g. Anderson et al., 2008; Lin and Hopmans, 2011), and the Terrestrial Environmental Observatories (TERENO) in Germany where the starting point was processes at the hydrological-ecological interface (Zacharias et al., 2011). While these observatories bear a lot of resemblance to the more traditional research catchments, they differ in three important ways. (a) Similar to astronomical and meteorological observatories, their objective is to provide long-term facilities that transcend the lifetime of individual projects. (b) Even more so than their more traditional counterparts, they are geared towards performing interdisciplinary research. (c) Often they are designed as networks to assist in performing collaborative science within the research community. Indeed, long-term interdisciplinary research in networks may be the hallmark of catchment-scale experimental research in an era where "Humans may no longer be treated as boundary conditions but should be seen as an integral part of the coupled humannature system... [and] the coupling between the geoscience disciplines... gets more important." (Blöschl et al., 2015, p. 17).

Establishment of research catchments or hydrological observatories may be either driven by management questions as was the case with much of the early experimental work, or by fundamental research questions, and the two aims may feed into each other. In both instances, the experimental or monitoring set-up must be designed in a way that enables the critical research questions to be tested. The classical example are paired catchment studies (e.g. Brown et al., 2005) where the effects of forest management on the hydrological cycle are studied with a similar, untreated catchment used as a control. Differences in the observations between these two catchments are then used to test hypotheses on, e.g. the effects of forest on water yield. Again, a classical hypothesis to be tested by this set-up is that forest cutting will increase water yield from the catchment. In the Coweeta, for example, "the largest water yield increases occurred the first year after cutting when evapotranspiration (Et) was most reduced due to minimal leaf area index (LAI). As vegetation regrew, LAI and Et increased and streamflow declined logarithmically, until it returned to the pre-treatment level by five to six years." (Elliott and Vose, 2011; p. 906). For more complex hypotheses, the experimental or monitoring set-up must be 
more elaborate in order to allow the hypothesis testing in a meaningful way.

The purpose of this paper is to illustrate how the experimental or monitoring set-up of an observatory can be established in a way that allows meaningful hypothesis testing, and to communicate the lessons learned from the experiences with the Hydrology Open Air Laboratory (HOAL) in Petzenkirchen, Austria. We will first present the science strategy of the set-up of such an observatory, discuss the implementation of the HOAL, give examples of the hypothesis testing and summarise the lessons learned.

\section{Science strategy of the HOAL}

The success of a research programme hinges on whether new, cutting-edge scientific findings are achieved. The HOAL observatory is designed to facilitate cutting-edge research by providing long-term experimental infrastructure, fostering interdisciplinary collaboration and encouraging networking within the science community. All three aspects are considered through the prism of the hypotheses to be addressed.

\subsection{Long-term experimental infrastructure}

Some of the most interesting science questions require longterm observation. These include questions related to hydrological change where one aims at detecting differences of hydrological fluxes and/or processes between decades. Another such question relates to hydrological extremes, since the likelihood of observing extreme events increases with the observation period. At the same time, long-term infrastructure can most efficiently be used if a range of complementary research questions is addressed that all build on that infrastructure, i.e. where the synergies of different questions are exploited. To cater for a range of questions, a nested approach was therefore adopted for the HOAL related to overarching science questions and specific hypotheses (Fig. 1).

\subsubsection{Overarching science questions}

First, overarching science questions were identified that were relevant for advancing the fundamental understanding of water-related flow and transport processes at the catchment scale. These were defined in a broad way and included the following.

- What are the space-time patterns of flow paths and evaporation in a small agricultural catchment?

- What are the space-time patterns of erosion and sediment transport processes in the catchment and what are their driving forces?

- What are the processes controlling nutrient and faecal pollution dynamics in the catchment?
These questions are aligned with the interests of the individuals and institutions involved in the context of prior experience, societal relevance and funding opportunities. The site location, the research student dissertation topics, and the base monitoring were selected based on the overarching questions.

Site location: selection of the site was guided by the ability to address the overarching science questions. Importantly, much of the research is related to runoff generation. It was therefore deemed important to select an area with many different runoff generation mechanisms in the same catchment to make the scientific findings applicable to a wide spectrum of catchments around the world. Questions such as erosion and nutrient dynamics are usually associated with agricultural practices, which was another criterion for selecting the site.

Dissertation topics: the topics of the dissertations were chosen in a way that a number of generations of research students can build on each other. The topics of the first generation students (2009-2013) were geared towards the more fundamental processes of water and matter flow in the catchment as well as soil moisture. The second generation (20122016) had more elaborate topics such as microbial processes, land-atmosphere interactions and linkages to the deep subsurface. The third generation of students will, again, build on these findings and address upscaling and hydrological change more explicitly. The fourth generation of students will be concerned with how all of these findings can be generalised to other climatic and management conditions around the world.

Base monitoring: all overarching research questions require an understanding of the hydrological fluxes with high spatial and temporal detail. Consequently, a substantial number of high-resolution raingauges and stream gauges were chosen as the base monitoring set-up. Locations of runoffrelated measurements were carefully considered to sample different runoff mechanisms. At the catchment outlet, basic chemical and physical parameters were monitored by online sensors and regular grab sampling. To complement these, a weather station was set up to monitor the energy fluxes at the land-atmosphere interface. Spatial sampling to characterise the catchment included Lidar for high-definition topography, soil mapping and sampling.

\subsubsection{Specific hypotheses}

Nested into the overarching science questions, specific hypotheses were defined, dedicated monitoring and sampling was performed, and individual experiments were conducted, some of which were repeated with controlled boundary conditions.

Dedicated monitoring and sampling: a soil moisture network within the catchment was set up to understand the spatial soil moisture distribution and link it to remotely sensed soil moisture. Three eddy-correlation stations were set up to 


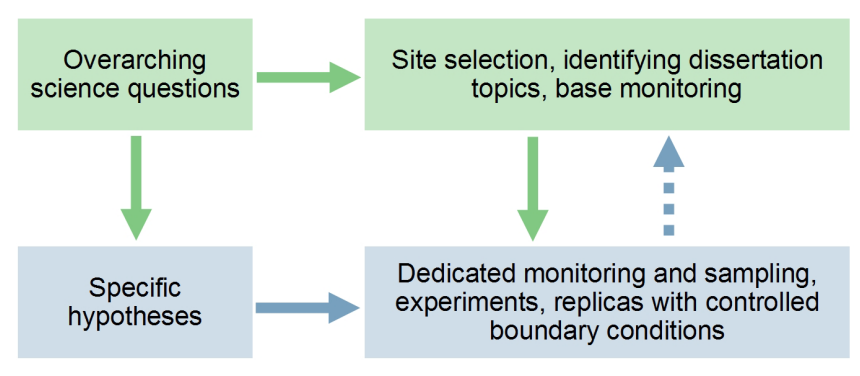

Figure 1. Interplay of hypotheses and experimental planning in the HOAL.

understand the spatial distribution of land-atmosphere interactions. Faecal indicators were monitored to test alternative measurement methods and understand the dynamics of faecal contamination, and water quality characteristics were monitored at a number of locations to understand nutrient fluxes (Exner-Kittridge et al., 2013).

Individual experiments: field campaigns were conducted over limited periods of time to obtain more in-depth understanding of the processes at the field scale. Examples include tracer tests in the stream to elucidate stream aquifer interactions and a field campaign dedicated to measuring transpiration and bare soil evaporation separately in a field of maize.

Repeated experiments with controlled boundary conditions: a small number of experiments were conducted with controlled boundary conditions. Examples include resuspension experiments were sediment-free water was pumped into the stream to understand the sources of suspended sediments at the beginning of events (Eder et al., 2014) and an experiment where soil plots were prepared to a prescribed roughness and moisture, which were then measured by Lidar to understand the controls on Lidar response.

New instruments and new data transmission technologies are of particular interest in the HOAL, as detailed in Sect. 3.2.2 of this paper. More detailed examples of how instrumentation and experimental set-up were selected on the basis of the specific hypotheses are given in Sect. 4.

\subsection{Interdisciplinary collaboration}

One of the hallmarks of an observatory is its ability for fostering cooperation across the disciplinary boundaries. In the case of the HOAL much of the research is conducted within the frame of the Vienna Doctoral Programme on Water Resource Systems (Blöschl, et al., 2012). The programme is funded by the Austrian Science Funds and aims at producing top graduates capable of conducting advanced, independent research of the highest international standards which cuts across multiple disciplines. The HOAL is therefore a natural platform for the Programme and benefits from its integration strategy. The Programme enables integration between disciplines that ensures that students can address more complex science questions than is possible through individ- ual dissertations. The main strategy for achieving this consists of organising the research through joint groups, joint research questions, and joint study sites. One of the joint study sites is the HOAL.

As an example, the concept of integration between the research of the nine doctoral students currently working in the HOAL is illustrated for one of the overarching science questions, i.e. "Space time patterns of flow paths and evaporation". Atmospheric scientist Patrick Hogan is investigating the soil moisture and land use controls on spatial evaporation patterns within the catchment. One specific hypothesis Patrick Hogan is testing is that the relative importance of soil moisture controls exceeds that of topographic controls at all times of the year. As evaporation is an important flux in the HOAL it will directly affect soil moisture (of interest to remote sensing specialist Mariette Vreugdenhil) and indirectly affect the flow paths (of interest to hydrogeologist Michael Exner-Kittridge who deals with nutrient fluxes). Structural engineer Abbas Kazemi Amiri is taking advantage of the eddy-correlation systems and conducts measurements of the dynamic wind loading of the mast structure to understand the interactions of water resource structures with wind, and specifically the role of fatigue. Conversely, Patrick Hogan can make use of the expertise and research progress of other students by testing the spatial distribution of evaporation obtained by his eddy-correlation instrumentation against observed runoff volumes in different parts of the catchment. Hydrologist Rasmiaditya Silasari's thesis quantifies the spatial organization of the flow patterns. One specific hypothesis she is testing is that spatial connectivity is a major determinant of the flow rates and flow dynamics. The numerical hydrological simulations she conducts for testing her hypotheses are directly relevant to Mariette Vreugdenhil for interpreting spatial soil moisture.

\subsection{Networking within the science community and beyond}

Another key characteristic of observatories is that they are embedded into a network of scientists to maximise the opportunities of producing novel and societally relevant research. Networking of the HOAL has therefore been designed at a number of levels.

The TU Wien - IKT collaboration: at the centre of the HOAL stands the collaboration between a number of institutes and centres of the Vienna University of Technology (TU Wien) and the Institute for Land and Water Management Research (IKT) of the Federal Agency for Water Management. The expertise of a number of TU Wien institutes is brought together through their affiliation with the Centre for Water Resource Systems at TU Wien, involving professors from structural mechanics, remote sensing, hydrology, hydrogeology and water quality. Each institute operates their own in-house laboratories in their area of specialisation. In addition, the IKT has a long standing expertise in measuring 
and modelling soil water, sediments and nutrients with a focus on field work. They have operated experimental sites for decades and also operate a physical and chemical soil laboratory and workshop.

Collaborations with instrument companies: a second level of networking and collaboration takes place with some of the providers of the instrumentation. Although most of the instrumentation has simply been purchased from the vendors, for a number of providers a joint venture has been embarked upon to test new instrumentation and methods. One such collaboration is with the Microtronics company regarding telemetering data from the catchment to the central server and data management. Another is with the VWM (Vienna Water Monitoring) company regarding testing novel devices for automated measurements of a proxy parameter of microbial faecal pollution in the stream of the HOAL under field conditions (Farnleitner et al., 2002; Ryzinska-Paier et al., 2014).

Collaborations with other research institutions: a range of collaborations with both national and international research institutes and agencies are under way, most of which focus on testing a particular hypothesis. A collaboration with the Austrian Institute of Technology (AIT) focuses on stable isotope analyses to understand water age, a collaboration with the International Atomic Energy Agency (IAEA) is geared to testing a cosmic ray soil moisture sensor against the soil moisture network, and a collaboration with the Helmholtz Centre for Environmental Research (UFZ) deals with understanding water isotopic signatures in a regional context. HOAL is one of the ground truthing sites of the NASA's SMAP (soil moisture active passive satellite) mission. Collaborations with additional institutes are being planned. The doctoral students working in the HOAL are entitled to spend a semester abroad with a research institution of their choice. This provides further opportunity to knit a strong network of collaborations with leading groups around the world in their field of expertise.

Communication and outreach: visibility of the research output hinges on suitable dissemination of the research results at a range of scales. Dissemination has therefore been designed as a multi-scale process involving the university (e.g. workshops and seminars within the university, email and website communication), the national and international scientific communities (through journal papers, conference presentations, and a guest scientist programme) and the general public through a range of outreach activities (e.g. newspaper, television and radio interviews with scientists working in the HOAL, as well as regular meetings with the local community).

\section{Implementation}

\subsection{Site selection and hydrological characteristics}

\subsubsection{Site selection}

Since many of the questions are related to runoff generation it was considered important to select an area with many different runoff generation mechanisms in the same catchment. Also, as the interest was on experimental hydrology, a catchment scale of a square kilometre or less was envisaged. A small catchment near Petzenkirchen, Lower Austria, was found to be ideally suited. In this catchment a wide range of runoff generation mechanisms occurs, including infiltration excess overland flow, re-infiltration of overland flow, saturation excess runoff from wetlands, tile drainage flow, shallow aquifer seepage flow and groundwater discharge from springs. The multitude of runoff generation mechanisms in the catchment provides a genuine laboratory where hypotheses of flow and transport can be tested, either by controlled experiments or by contrasting sub-regions of contrasting characteristics. This diversity also ensures that the HOAL is representative of a range of catchments around the world and the specific process findings from the HOAL are applicable to a variety of agricultural catchment settings.

As many of the overarching science questions are related to erosion and nutrients, it was considered an advantage that most of the catchment is used for agricultural purposes where sediment and nutrient fluxes tend to be bigger than for forested or urban settings. The crops include winter wheat and maize, which allows examination of the effect of different crops on the hydrological processes. Manure and fertiliser application are accurately known from farmers' bookkeeping, which is useful for estimating nutrient and faecal pollution inputs. Part of the catchment is pasture and part of it is forested, which opens up more comparative research opportunities.

The catchment selected also had other, more practical, advantages over other catchments. Importantly, it is very convenient from a logistic point of view. It is located within walking distance of the premises of the Institute for Land and Water Management Research, which greatly facilitates the day-to-day maintenance of the instruments and experimental set-ups. Because of the proximity to the institute, the instruments can be connected to the power grid which, again, has major advantages as it avoids battery failures $-\mathrm{a}$ frequent cause of data loss. Finally, the instruments can be connected to a high-speed glassfibre local area network which is very useful for data management and remote monitoring of the functioning of the instruments and the short-term planning of experiments. Alternative potential site locations such as the Löhnersbach, a previous research catchment of the TU Wien (Kirnbauer et al., 2005), while interesting hydrologically, did not meet the criteria of logistic convenience. 
An additional bonus for the selection of the site is that runoff measurements at the catchment outlet started in 1945 (Blümel und Klaghofer, 1977; Turpin et al., 2006; Strauss et al., 2007), which helps put the recent observations into a longer-term context.

\subsubsection{Catchment description}

The Petzenkirchen HOAL (Hydrology Open Air Laboratory) catchment is situated in the western part of Lower Austria $\left(48^{\circ} 9^{\prime} \mathrm{N}, 15^{\circ} 9^{\prime} \mathrm{E}\right)$ (Fig. 2). The catchment area at the outlet (termed MW) is 66 ha. The elevation of the catchment ranges from 268 to $323 \mathrm{~m}$ a.s.l. with a mean slope of $8 \%$. At present, $87 \%$ of the catchment area is arable land, $5 \%$ is used as pasture, $6 \%$ is forested and $2 \%$ is paved. The crops are mainly winter wheat and maize.

The climate can be characterised as humid with a mean annual temperature of $9.5^{\circ} \mathrm{C}$ and a mean annual precipitation of $823 \mathrm{~mm} \mathrm{yr}^{-1}$ from 1990 to 2014 . Precipitation tends to be higher in summer than in winter (Fig. 3, Appendix A). Crop evapotranspiration $\left(\mathrm{ET}_{c}\right)$ estimated by the FAO (1998) method using local climate data and crop growth information for this period was $471 \mathrm{~mm} \mathrm{yr}^{-1}$. Annual evapotranspiration estimated by the water balance ranged from 435 to 841 with a mean of $628 \mathrm{~mm} \mathrm{yr}^{-1}$ (1990-2014) (assuming deep percolation is negligible). The natural surface water outlet of the catchment is known as the Seitengraben stream. Mean annual flow from the catchment in this stream is $4.1 \mathrm{~L} \mathrm{~s}^{-1}$ (or $195 \mathrm{~mm} \mathrm{yr}^{-1}$ ) (1990-2014). Mean flows tend to peak in the spring (Fig. 3). The largest flood events on record occurred in 1949 and 2002 with estimated peak discharges of 2.8 and $2.0 \mathrm{~m}^{3} \mathrm{~s}^{-1}$, respectively. The highest discharge in recent times occurred in summer 2013 with $0.66 \mathrm{~m}^{3} \mathrm{~s}^{-1}$. The subsurface consists of Tertiary sediments of the Molasse zone and fractured siltstone. The dominant soil types are Cambisols and Planosols with medium to poor infiltration capacities. Gleysols occur close to the stream (Fig. 4).

The HOAL is special in that many runoff generation mechanisms can be observed simultaneously in different parts of the catchment (Fig. 5). Due to shallow, low permeable soils and the use of the catchment area as agricultural land, the concave part of the catchment was tile drained in the 1940s in an effort to reduce water logging. The estimated drainage area from the tile drains is about $15 \%$ of the total catchment and can be divided into two bigger systems in the south-western part of the catchment and four smaller drainage systems in the north-eastern part. The pipes drain into the main stream at four locations. Two tile drain systems (Sys1, Sys2) do not dry out during the year, while two are ephemeral (Frau1, Frau2) (see Fig. 7). The uppermost $25 \%$ of the stream was piped in the 1940s to enlarge the agricultural production area. The pipe enters the main stream at inlet Sys4. Its flow dynamics and chemistry are similar to those of the permanent tile drains as it drains the surrounding soil.
There are two clearly visible springs that directly discharge into the stream. These are Q1 and K1. The water from Q1 originates from a fractured siltstone aquifer with distinct hydrologic and chemical characteristic from those of other point sources along the stream. The hydrologic dynamics and chemical characteristics of $\mathrm{K} 1$ are more similar to the perennial tile drainages. Q1 is perennial, while $\mathrm{K} 1$ is not.

In the south-eastern part of the catchment is a small wetland close to the stream which permanently seeps into the stream via two rivulets (A1, A2). The wetland is fed by springs at the upper part of the wetland and usually responds very quickly to all types of rainfall due to its high saturation state.

During low-intensity events in summer, the flow in the main stream responds to rainfall with substantial delay as the soil usually offers a lot of storage capacity, depending on soil moisture. A mixture of tile drainage water, diffusive inflow from the shallow aquifer, spring water, and surface water from the wetland tends to feed the stream. During major storms, saturation overland flow occurs across the fields (mainly in the depression areas along the talweg and close to the stream) which enters the stream at two (E1, E2) or three locations, depending on the magnitude of the event. The overland flow causes gully erosion.

During high-intensity thunderstorms in summer and spring, infiltration excess overland flow tends to occur with a very substantial, fast contribution from the tile drainage system. During infiltration excess overland flow events, all forms of erosion from interrill to gully erosion may occur on the fields that are poorly covered by crops (such as bare soil after soil management), but sedimentation immediately occurs when the sediment laden water enters a field with better cover (such as wheat). During very dry periods in summer, the high clay contents will cause shrinking cracks which act as macropores for re-infiltration during subsequent events.

In winter, rain-on-snow runoff may occur as saturation overland flow during large events leading to gully erosion. In fact, this is when most of the overland flow occurs during the year. However, the main runoff generation mechanism in winter is through lateral subsurface pathways (shallow subsurface preferential flow paths, drainage pipes). Even minor events (of, say, $5 \mathrm{~mm}$ ) will lead to a significant increase in streamflow due to high soil moisture during the winter. After freezing periods, when the soil is still frozen, infiltration excess overland flow may occur.

\subsection{Setting up the HOAL and instrumentation}

Setting up the base monitoring and the dedicated monitoring and sampling was guided by the overarching science questions and the specific hypotheses. 


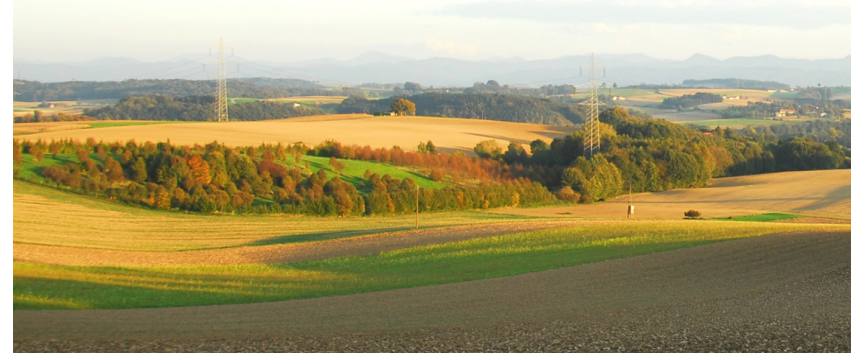

Figure 2. View of the Petzenkirchen HOAL catchment looking south (trees in the centre of the photo constitute the riparian zone of the Seitengraben stream).

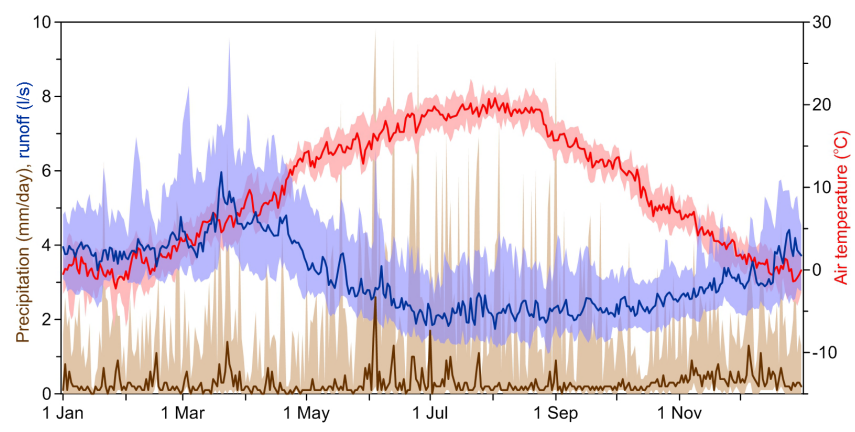

Figure 3. Precipitation and air temperature at the weather station, and runoff at the catchment outlet (MW) of the HOAL. Lines show medians of the period 1990-2014, shaded areas the 25 and $75 \%$ percentiles based on the data aggregated to daily values.

\subsubsection{Basic infrastructure and monitoring}

Planning of the HOAL started in 2008. In September 2009 the Vienna Doctoral Programme on Water Resource Systems started and the financial resources for the base instrumentation were made available through the TU Wien. In line with the overarching science questions, the instrumentation was designed for a high spatial and temporal resolution which involves substantial power consumption. Consequently, a mains cable was run from the nearest connector a few hundred meters outside the catchment along the stream to the weather station to enable $380 \mathrm{~V}$ electric power supply to the instruments. To facilitate maintenance of the instruments, data storage and the short-term planning of experiments, a high-speed glassfibre cable was run from the premises of the Institute for Land and Water Management Research into the HOAL to provide a local area network (LAN) for data transmission. The glassfibre network allows fast streaming of the data and is less susceptible to damage due to lightening than electrical transmission lines. Subsequently, a range of instruments was installed as the basic monitoring set-up to measure dynamic data. All are operated at a temporal resolution of $1 \mathrm{~min}$ with the exception of the

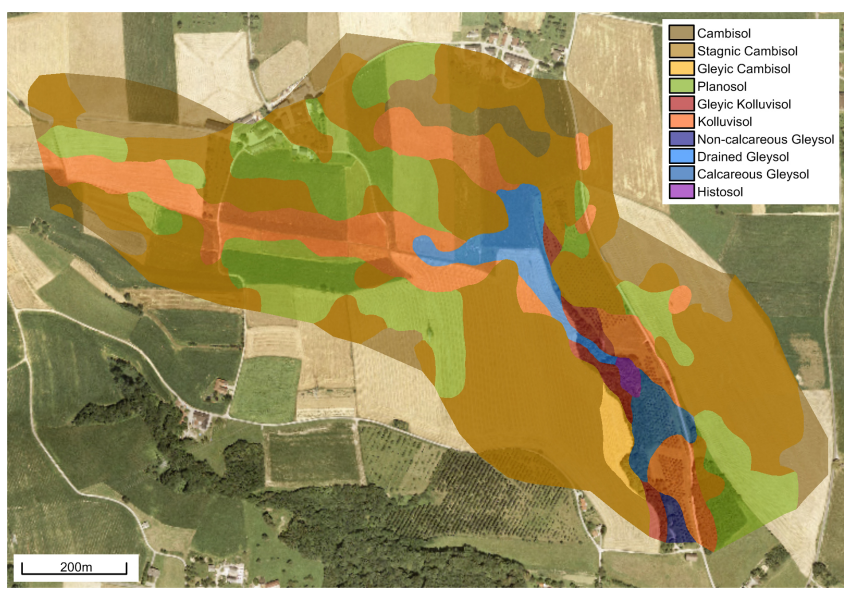

Figure 4. Soil types in the HOAL.
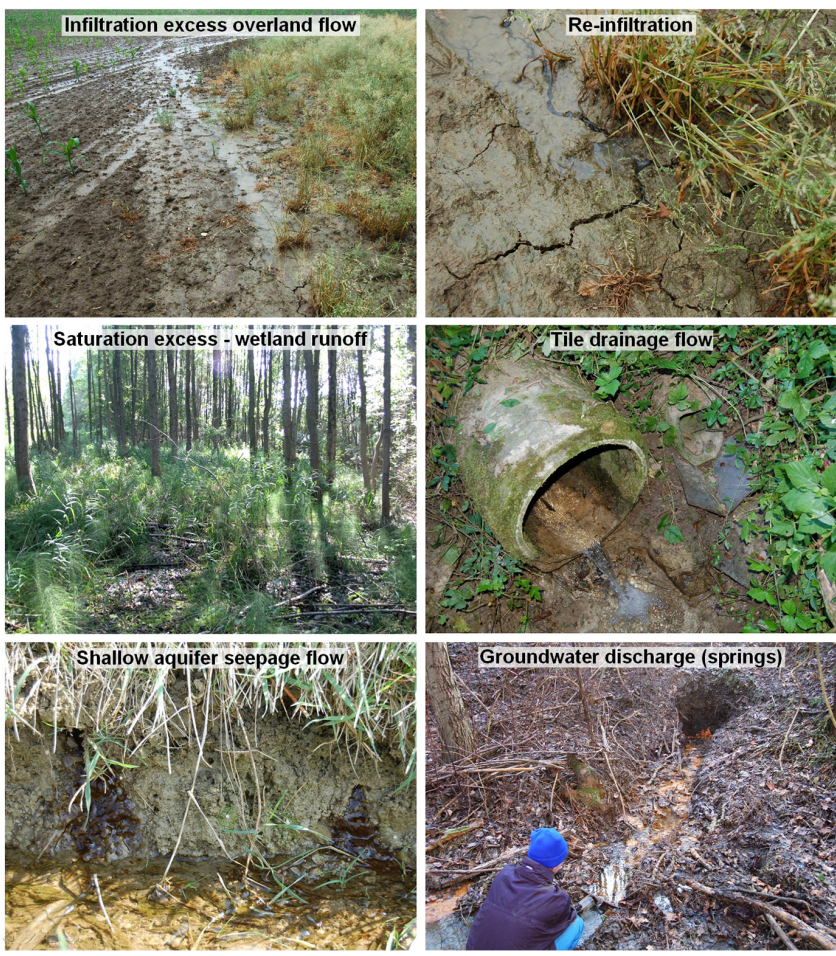

Figure 5. Runoff generation mechanisms in the HOAL.

piezometers, where groundwater levels are recorded at temporal resolutions of 5 to $30 \mathrm{~min}$.

Atmospheric processes: four raingauges were installed to monitor spatial rainfall patterns which were strategically placed to cover spatial rainfall patterns well.

Atmospheric and soil processes: monitoring at the weather station located approximately in the centre of gravity of the catchment includes air temperature, air humidity, wind speed and direction (all at three heights), incoming and outgoing solar and long-wave radiation, wind load on the construction, 
raindrop size distribution, snow depths, soil heat flux and soil temperatures at different depths.

Surface water: a total of 12 flumes were installed within the catchment to monitor discharge at 1 min resolution from the inlet piped stream, tile drains, erosion gullies, springs and tributaries from wetlands. These flumes are the backbone of the HOAL. All flumes were calibrated in the Hydraulic Laboratory of the TU Wien to obtain a reliable stage-discharge relationship.

Surface water: at the catchment outlet, the existing Hflume (dating from 1945 with a number of changes since) was upgraded in 2009 . The maximum discharge capacity was increased and a number of additional sensors were installed including water temperature, electrical conductivity, turbidity (two probes from different makes), chloride, $\mathrm{pH}$, and nitrate. Grab samples are taken weekly for a range of chemical analyses including suspended solids and various compounds of nutrients. Additionally, autosamplers take water samples during events. A video camera was installed to monitor the water level in the flume and the functioning of the instruments.

Groundwater: 23 piezometers were installed within the catchment where groundwater level and water temperature are monitored. Most of the piezometers are located along transects perpendicular to the stream to help understand stream-aquifer interactions. Two additional air pressure sensors were needed to correct the readings of the pressure transducers for the air pressure fluctuations.

Table 1 and Appendix B give more details of the instruments. All of these instruments are connected to data loggers (some of them through interfaces) where the data are stored temporarily. Most of the data loggers are then directly connected to a computer at IKT through the glassfibre LAN. These include the loggers of the discharge pressure transducers, the turbidity measurements, the water chemical parameters and the instruments at the weather station. The raingauges are connected through a GSM (mobile phone) module. The data of the piezometers and the movable eddycorrelation stations are stored locally and read out manually at regular intervals.

To complement the base monitoring of the dynamics of the hydrological flow and transport processes at specific locations, a number of spatial surveys were conducted after setting up the HOAL, which included a Lidar survey, aerial photographs, soil mapping and sampling, and collection of agricultural data (Table 2). Further details are given in Appendix B, Figs. 6 and 7.

\subsubsection{Dedicated monitoring and experiments}

Dedicated monitoring and experiments were more specifically geared towards the testing of individual hypotheses (see Sect. 4 for examples) and involve new instruments and new data transmission technologies in addition to proven technology. Three eddy-correlation stations were set up in
2012 and 2013 to understand the spatial distribution of landatmosphere interactions. As evaporation is an important flux in the HOAL, it will directly affect soil moisture and flow paths of interest to other HOAL research questions. One set of instruments has been set up at the weather station location, using a closed path device. Additionally, two mobile stations are deployed (using open path devices) based on a site rotation plan to optimise the locations for each sensor relating to the factors of interest: topography, soil type and moisture and vegetation. The data are processed offline using dedicated software (Mauder and Foken, 2011) to provide 30 min values for the sensible, latent heat and $\mathrm{CO}_{2}$ fluxes. Soil heat flux and net radiation sensors are also installed to complete the energy balance. Scintillometer measurements of aggregated fluxes over a line of about $150 \mathrm{~m}$ are made for comparison to obtain momentum flux, sensible heat flux and information on the turbulent parameters of the air. Acceleration sensors (accelerometers) are installed on the guyed mast of the weather station to evaluate the fatigue of water related structures caused by the fluctuating components of wind. For the elements of steel structures (such as poles of water supply towers) fatigue damages due to the high cyclic wind-induced vibration are a relevant failure mechanism. Another step is to identify the wind loads inversely from the measured structural response and correlate them to the wind statistics from eddy-correlation measurements. The wind load identification follows the general lines of the experiments already accomplished at the TU Wien laboratory of structural model dynamics (Kazemi and Bucher, 2015).

A soil moisture monitoring network was set up to understand the effect of small-scale variability of landscape characteristics on the microwave response of satellite sensors (see Sect. 4.3). Since soil moisture is such a key parameter, a better understanding of its space-time patterns will also be useful to other processes in the HOAL including evapotranspiration and runoff generation. The network uses wireless transmission technology based on the ZigBee protocol (Bogena et al., 2010). Time domain transmission sensors were installed at four depths below ground surface. One of the difficulties with measuring soil moisture in agricultural catchments is that it is not possible to install the sensors permanently in the field. As a consequence, 20 stations were installed permanently on pasture, while 11 stations are temporary, which are removed and replaced once or twice a year in accordance with the agricultural manipulations on the fields. Monitoring of saturation patterns within the catchment is conducted using a video camera to understand the space-time patterns and connectivity of surface flow following the pattern comparison paradigm of Blöschl et al. (1991) and Parajka et al. (2012). This is complementary to the soil moisture network by providing visual observation with better spatial resolution. Pictures of overland flow generation provide a visual assessment of saturation patterns and are useful for validating distributed models of surface runoff (Grayson et al., 2002; Horvath et al., 2015). 


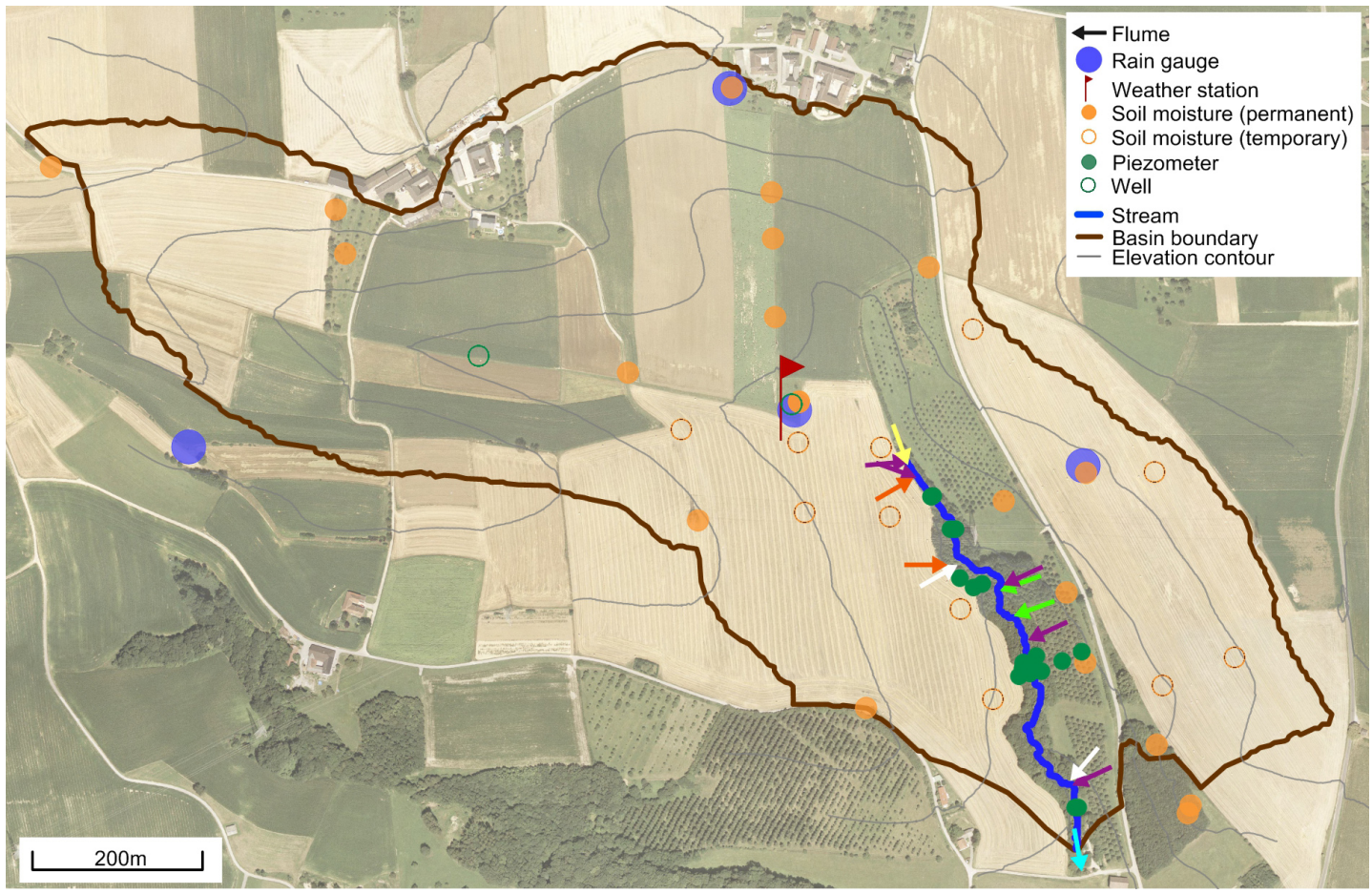

Figure 6. Instrumentation in the HOAL catchment (see Tables 1 and B1).

To understand the dynamics of nutrients such as phosphorus and nitrogen and their compounds, a water quality monitoring network was installed at the tributaries within the HOAL to complement the base monitoring at the catchment outlet (see Sect. 4.2). Flumes for overland flow from the fields (erosion gullies), the wetland, tile drains and the springs were equipped with in situ sensors for electrical conductivity, temperature, turbidity, $\mathrm{pH}$, nitrate and chloride sampling at $1 \mathrm{~min}$ intervals. While the high sediment concentrations in the HOAL facilitated the sediment process analyses, they turned out to be a challenge for monitoring the water quality parameters, as the stilling wells in which sensors are usually placed tended to silt up quickly. A new device was developed, termed the Water Monitoring Enclosure (WME), which allows in situ monitoring of water quality parameters for highly dynamic, sediment-laden streams (Exner-Kittridge et al., 2013). The WME ensures a minimum internal water level which keeps the monitoring equipment submerged even when there is no flow into the enclosure. Four WME and six autosamplers were installed throughout the catchment for event sampling. Grab sampling is performed monthly at the tributaries, in addition to the weekly sampling at the catchment outlet, and analysed for a range of parameters including stable isotopes. Four enzymatic analysers were set up at the catchment outlet to understand the dynamics and pathways of faecal pollution and to test the instruments for real-time surface water monitoring (see Sect. 4.4). The devices sample stream water at intervals of 1 or $3 \mathrm{~h}$. The results from the de- vices are compared for different set-ups with laboratory analyses of water samples to understand the strengths and limitations of the instruments in an on-line mode, and interpreted in the context of a range of physical and chemical parameters for events with contrasting characteristics (e.g. fast and short response times, dry and wet antecedent soil moisture) to shed light on the processes of microbial pollution.

Sediment monitoring and experimentation were conducted to understand the sources and pathways of sediments within the catchment (see Sect. 4.1). Turbidity is monitored at both erosion gullies along with autosamplers to be able to calibrate the sediment-turbidity relationships for each event separately (Eder et al., 2010). Further autosamplers are located at the inlet of the piped stream and some of the tile drains on the right bank to investigate subsurface sediment transport. Aerial photographs are taken to identify erosion patterns and calculate eroded soil volumes after erosive rainfall events. To understand sediment deposition and resuspension in the stream, flushing experiments were conducted, where sediment-free water was pumped into the source of the stream and flow rates, and sediment and solute concentrations as well as grain size distributions were measured (Eder et al., 2014).

To explore the stream-aquifer interactions, several stream tracer tests were performed in the main stream. One set of tracer experiments was performed during winter baseflow conditions (where evaporation can be assumed to be negligible). Bromide was injected as a tracer and bromide con- 


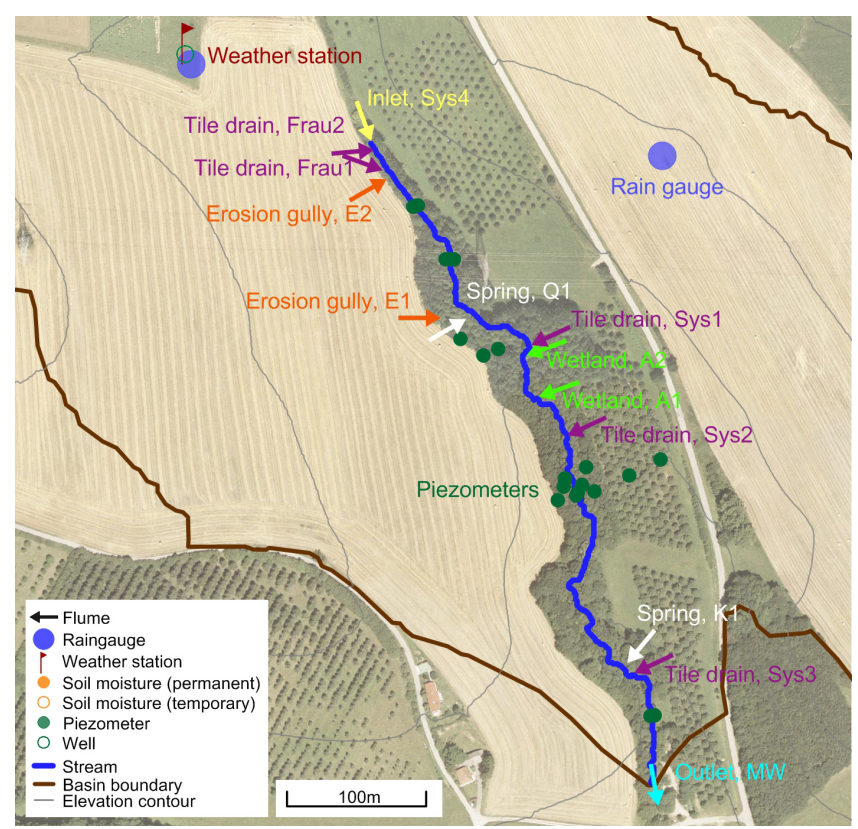

Figure 7. Detail of instrumentation in the HOAL catchment (see Tables 1 and B1).

centrations and flow were measured for five locations along the stream. This allowed the estimation of stream bank fluxes (Exner-Kittridge et al., 2014). An infrared camera was used to identify hotspots of groundwater recharge into the stream. Mass balances over sections of the stream were used to determine the role of near-stream riparian trees in the daily fluctuations of the stream flow during low-flow conditions. A number of geophysical surveys were conducted to improve the delineation of hydrogeological heterogeneities and processes in the subsurface. Initially, a series of measurements using ground-penetrating radar were performed in 2010 for the characterisation of drainage pipes. Imaging surveys are being started with the induced polarization method for delineating the aquifer geometry and hydrogeological structures such as preferential flow paths. Application of the spectral-induced polarization method at different frequencies is planned to gain information on hydraulic conductivity and changes in the subsurface associated with microbial activity (e.g. Flores Orozco et al., 2011, 2013, 2015). Low-induction number electromagnetic induction methods will permit the collection of data at extensive areas with reduced acquisition times. Tables $\mathrm{B} 1$ and $\mathrm{B} 2$ give details on the instrumentation and the associated laboratory analyses.

\subsection{Managing the HOAL}

Meaningful hypothesis testing in an observatory not only requires careful planning of installation of instruments and conducting the monitoring and the experimentation, but also coordination of the research between the groups involved, maintenance of the instruments, dealing with landowners, and data management.

\subsubsection{Coordination of research}

One of the main strengths of this kind of observatory comes from the synergies between a critical group of people conducting related research. In the HOAL, currently more than 20 researchers are involved plus support staff. Nine dissertation projects focussed on the HOAL are being conducted. While observatories sometimes adopt a top-down approach where the individual research activities are subsidiary to the main goal, a slightly different approach has been adopted in the HOAL. A general master plan for the research to be conducted was defined as the overarching sciences questions. These were specified in the research proposals of the Doctoral Programme on Water Resource Systems that were submitted to the Austrian Science Funds (Blöschl et al., 2012). The research proposals also included more specific hypotheses. When actually implementing the research, the individual doctoral students were given considerable freedom in specifying their own hypotheses and their experimental/monitoring set-ups. This then led to an iterative network structure of the interactions between the research of the students. Figure 8 illustrates the general concept of implementation. For each hypothesis, the individual steps of implementation consisted of (i) planning of the dedicated monitoring and experiments, (ii) conducting monitoring and experiments, (iii) data analysis and hypothesis testing, and (iv) research write up. Depending on the outcomes of the experiments, these steps would be repeated in an iterative way. At the same time other hypotheses are tested in the HOAL (by the same or other students). These interact, as indicated by the double arrows in Fig. 8. The interactions occur at all four steps of the research, from the planning to the write up. The main advantages of this iterative, network-based process of conducting hypothesis testing are its flexibility and the encouragement of creative thinking by the students.

The Doctoral Programme on Water Resource Systems is an ideal setting for this exchange as it is specifically geared towards fostering collaboration between students, including from different disciplines. As part of the doctoral programme, each student is encouraged to develop collaborations through joint supervision (each student has two supervisors), regular research cluster meetings focusing on research themes, and annual and 6-monthly symposia that bring all research students and supervisors together for 1 or 2 days for research presentations, posters and discussion sessions.

\subsubsection{Maintenance of instruments}

The overall responsibility of coordinating the maintenance of the instruments lies with the HOAL manager who draws the maintenance plans and coordinates or supports any repairs and replacements. The manager also coordinates the instal- 
Table 1. Instrumentation in the HOAL (most of which has a 1 min time resolution). Most data are transmitted to the server at the institute by glassfibre cable. For details, see Appendix B; for locations, see Figs. 6 and 7.

\begin{tabular}{|c|c|c|c|c|}
\hline Compartment & Variables & Locations & $\begin{array}{l}\text { Number of } \\
\text { stations }\end{array}$ & $\begin{array}{l}\text { Basic/ } \\
\text { dedicated }\end{array}$ \\
\hline Atmosphere & Precipitation intensity & Within (or close to) catchment & 4 & $\mathrm{~B}$ \\
\hline Atmosphere & $\begin{array}{l}\text { Air temperature, humidity, wind speed and } \\
\text { direction (three heights); atmospheric pres- } \\
\text { sure, incoming and outgoing short-wave and } \\
\text { long-wave radiation, raindrop size distribu- } \\
\text { tion }\end{array}$ & Weather station & 1 & $\mathrm{~B}$ \\
\hline Atmosphere & $\begin{array}{l}\text { Carbon dioxide flux, latent heat flux, sensi- } \\
\text { ble heat flux, momentum flux (eddy correla- } \\
\text { tion) }\end{array}$ & Weather station and other locations & 3 & $\mathrm{D}$ \\
\hline Atmosphere & Sensible heat flux (scintillometer) & Within catchment & 1 & $\mathrm{D}$ \\
\hline Atmosphere & Wind load & Weather station & 1 & $\mathrm{D}$ \\
\hline Ground surface & Snow depth & Weather station & 1 & $\mathrm{~B}$ \\
\hline Ground surface & Saturation patterns (photos, video) & Within catchment & 1 & $\mathrm{~B}$ \\
\hline Surface water & $\begin{array}{l}\text { Discharge, electric conductivity, tempera- } \\
\text { ture, } \mathrm{pH} \text {, chloride, nitrate }\end{array}$ & Inlet: piped stream (Sys4) & 1 & $\mathrm{~B} / \mathrm{D}$ \\
\hline Surface water & $\begin{array}{l}\text { Discharge; partly electric conductivity, tem- } \\
\text { perature, } \mathrm{pH}, \text { chloride, nitrate }\end{array}$ & $\begin{array}{l}\text { Tile drains (Frau1, Frau2, Sys1, } \\
\text { Sys2, Sys3) }\end{array}$ & 5 & $\mathrm{~B} / \mathrm{D}$ \\
\hline Surface water & Discharge, turbidity & Erosion gullies (E1, E2) & 2 & $\mathrm{~B}$ \\
\hline Surface water & Discharge & Springs (Q1, K1) & 2 & $\mathrm{~B}$ \\
\hline Surface water & $\begin{array}{l}\text { Discharge; partly electric conductivity, tem- } \\
\text { perature, } \mathrm{pH} \text {, chloride, nitrate }\end{array}$ & Wetland runoff (A1, A2) & 2 & $\mathrm{~B} / \mathrm{D}$ \\
\hline Surface water & $\begin{array}{l}\text { Discharge, electric conductivity, tempera- } \\
\text { ture, turbidity, pH, chloride, nitrate, enzy- } \\
\text { matic activity, UV-Vis fingerprint, video im- } \\
\text { ages }\end{array}$ & Catchment outlet (MW) & 1 & $\mathrm{~B} / \mathrm{D}$ \\
\hline Surface water & $\begin{array}{l}\text { Runoff water samples (automatic samplers, } \\
24 \text { bottles each, event triggered) }\end{array}$ & $\begin{array}{l}\text { Inlet (Sys4), tile drain (Frau2), ero- } \\
\text { sion } \\
\text { gullies (E1, E2), catchment outlet } \\
\text { (MW) }\end{array}$ & 6 & $\mathrm{~B} / \mathrm{D}$ \\
\hline Soil & Soil heat flux, soil temperatures & Weather station & 1,2 & $\mathrm{~B}$ \\
\hline Soil & $\begin{array}{l}\text { Soil moisture, soil temperature (in four } \\
\text { depths, partly five depths) }\end{array}$ & Within catchment & 31 & $\mathrm{D}$ \\
\hline Soil & Soil moisture (cosmic ray) & Weather station & 1 & $\mathrm{D}$ \\
\hline Groundwater & $\begin{array}{l}\text { Groundwater level, temperature, partly air } \\
\text { pressure }\end{array}$ & Within catchment & 24 & $\mathrm{~B}$ \\
\hline
\end{tabular}

lation of new instrumentation and the set-up of experiments. An important part of the maintenance work relates to the base monitoring, and in particular the cleaning of the H-flumes at the stream tributaries. Some of the water quality sensors need regular cleaning to avoid biofilm formation and calcification. The sensors on the weather station are checked regularly for level position and cleanliness. The soil moisture sensors and the other sensors that are not connected to the power grid are checked regularly for power supply (change of batteries, cutting out grass to prevent solar panels from being overgrown). A regular schedule of checking the instrumentation is operated. In these tasks, the HOAL manager is assisted by a 
Table 2. Spatial surveys of catchment characteristics. For details see Appendix B.

\begin{tabular}{|c|c|c|c|c|}
\hline Survey & Variables & Spatial resolution & Date of survey & $\begin{array}{l}\text { Basic/ } \\
\text { dedicated }\end{array}$ \\
\hline Lidar & Digital elevation model & $0.5 \mathrm{~m}$ & March 2010 & B \\
\hline $\begin{array}{l}\text { Soil mapping through } \\
\text { auger holes }\end{array}$ & Soil type & $50 \mathrm{~m}$ grid & Spring 2010 & B \\
\hline Soil sampling by profiles & $\begin{array}{l}\text { Soil horizons, photos, colour, texture, } \\
\text { organic carbon, anorganic carbon, plant } \\
\text { available phosphorus and potassium and } \\
\text { pH of each soil horizon }\end{array}$ & $50 \mathrm{~m}$ grid & Summer 2010 & B \\
\hline Soil sampling by profiles & $\begin{array}{l}\text { Saturated and unsaturated hydraulic } \\
\text { conductivity, pF and bulk density of each } \\
\text { soil horizon }\end{array}$ & $50 \mathrm{~m}$ grid & $\begin{array}{l}\text { Summer 2012- } \\
\text { ongoing }\end{array}$ & $\mathrm{B}$ \\
\hline Geophysics & Georadar profiles & Four profiles & August 2010 & $\mathrm{D}$ \\
\hline Geophysics & Seismic profiles & Seven profiles & March 2011 & $\mathrm{D}$ \\
\hline Soil moisture survey & Soil moisture & $100 \mathrm{pts}$ & Spring 2014 & $\mathrm{D}$ \\
\hline $\begin{array}{l}\text { Aerial photographs from } \\
\text { powered paraglider }\end{array}$ & $\begin{array}{l}\text { Digital surface model, surface roughness, } \\
\text { soil loss volumes, erosion patterns }\end{array}$ & $\begin{array}{l}\text { Depending on } \\
\text { flight height }\end{array}$ & bimonthly & $\mathrm{D}$ \\
\hline $\begin{array}{l}\text { Agricultural data } \\
\text { interviews with } \\
\text { farmers }\end{array}$ & $\begin{array}{l}\text { Crops, cultivation period, seeding, } \\
\text { fertilization, plant protection, harvest times, } \\
\text { harvested biomass, fertiliser and manure } \\
\text { application }\end{array}$ & By field & Annually & $\mathrm{B}$ \\
\hline $\begin{array}{l}\text { Water withdrawal } \\
\text { interviews with } \\
\text { farmers }\end{array}$ & Water withdrawal from wells & $\begin{array}{l}\text { Two wells in catch- } \\
\text { ment }\end{array}$ & Annually & B \\
\hline
\end{tabular}

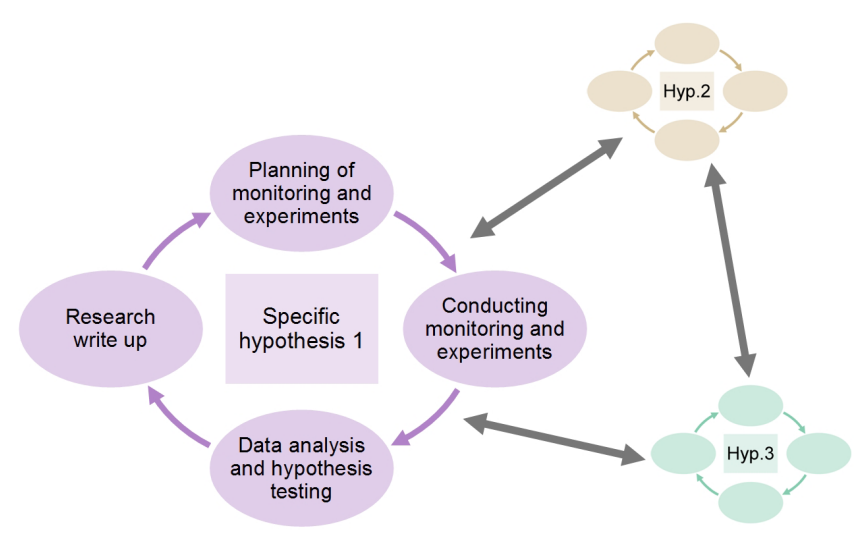

Figure 8. Network-based coordination of hypothesis-guided research.

number of local technicians with diverse expertise, including electronics.

Generally, each student is responsible for the proper set-up and operation of any dedicated monitoring and experimentation for their $\mathrm{PhD}$ research. There is, again, a set maintenance schedule. Maintenance and regular checking of the stations are coordinated with the HOAL manager and carried out by the students and the local technicians.

One of the main advantages of the HOAL is its location within walking distance of the premises of the Institute for Land and Water Management Research, which vastly facilitates the day-to-day maintenance of the instruments and experimental set-ups. Both the HOAL manager and the local technicians are based at the institute. Heavy rainfall events can be observed live and reference measurements can be taken during events. The operation of the auto samplers can be checked during events, to maximise the number of water samples from an event. After events associated with lightening the entire system is checked for operation (e.g. power outages).

To facilitate the exchange of information between the team members, a web-logbook has been specifically created for the HOAL. All activities within the HOAL are entered into the logbook including installation and maintenance of instrumentation, all sampling and surveying activities, and any other activities that are relevant to the operation of the HOAL. The web-logbook is a web application that allows access anywhere anytime by simply using a web browser. The main advantage of the logbook is that it sets a minimum stan- 
dard protocol for all the information relevant to operating the HOAL and its easy, instantaneous accessibility to all team members. The logbook is often accessed in the field during manual measurements. The software also features user management, search and import/export facilities.

\subsubsection{Landowners}

Observatories in most other geoscience disciplines, such as astronomy and meteorology, require relatively modest space on the land. Typically, the land is purchased by the operators of the observatory. In contrast, hydrology is about water and matter fluxes at the landscape scale, so the requirements regarding space are invariably more extensive, and purchasing the entire catchment of interest is rarely an option. Arrangements have therefore to be made between the operators of the observatories and the landowners. The arrangements in the HOAL involve

- permissions to use the land, and

- information on agricultural management practices.

Permissions to use land are needed for the permanent instrumentation (such as the weather station) as well as to access the fields for sampling and for the temporary sensors of the soil moisture network. Information on agricultural management practices is particularly important for estimating nutrient input and it is also very relevant for estimating other fluxes such as transpiration. In a number of instances specific tillage practices are part of hillslope experiments.

Agreements have been drawn up between the HOAL management and the landowners to make arrangements for both aspects. About half the land is privately owned by a total of nine farmers. The remaining land is state owned and managed by the Austrian agricultural research agency, which facilitates the collaboration with the HOAL team due to similar objectives. A small fee is paid as part of the agreement but, more importantly, a good working relationship is always sought. Any maintenance or experimentation activities in the field are planned in agreement with the landowners, in order to avoid obstructions of the daily agricultural routines. The HOAL manager makes an effort to introduce the doctoral students and their research to the farmers on site, e.g. when they meet by chance during sensor installations or field work. The farmers are given access to the weather data, which is generally appreciated. They also get Christmas presents and there is an annual open day where the students explain their recent research to the local community. The main source of income of the farms in the catchment is crop production for pig fattening. Fertiliser costs and fertiliser leaching as well as the problem of soil loss by erosion are important tasks farmers have to deal with. This makes them additionally interested in the research and the cooperation.

\subsubsection{Data management}

As indicated in Appendix B, most sensors are connected to a computer (IKT server, HOAL PC, Soil Net PC) at the IKT via a fast glassfibre LAN. A database, known as Mydatanet, is run on the IKT server and hosts most of the data. Mydatanet imports the data at $1 \mathrm{~min}$ intervals from the data loggers along the stream (discharge and water chemistry parameters) and the raingauges. Mydatanet features online access and a web-based graphical interface (Fig. 9) to the database which allows a regular check of data and fast identification of specific hydrologic situations and instrumentation failures. Mydatanet also provides for easy importing and downloading, user management, device administration and reporting.

Some sensors are connected through fast glassfibre LAN to dedicated computers. For example, the sensors of the weather station are connected to the HOAL PC, the sensors of the soil moisture network to the Soil Net PC where they are stored as files. Some data (such as the eddy-correlation data) are read out manually from the data loggers and uploaded on the data bases on the dedicated computers.

All measured data are stored as two separate layers. The first contains raw data as directly obtained by the instruments. These data are regularly screened for errors and inconsistencies. They are corrected or labelled as missing data according to a set protocol. The corrected data are stored in the second layer with data flagging and a processing report. Data quality check is an important step in data management not only for scientific usage of the data, but also for providing a direct feedback to maintaining and updating instrumentation configurations. All raw and processed data are exported from the various databases and uploaded in consistent CSV file format to an ftp server at TU Wien at daily and bimonthly (raw data) and 6-monthly (processed data) intervals. A backup of all data is performed on a daily basis by the grandfather-father-son method. Monthly backups of all databases are kept for 1 year.

The HOAL manager is responsible for the overall data management process. Two IT professionals (one at IKT, one at TU Wien) are responsible for the back up of the data and hardware maintenance. The quality check and the correction of the data are carried out by the research students as part of their $\mathrm{PhD}$ work. The data correction protocols are stored on the ftp server in simple readme text format.

\section{Examples of specific hypotheses}

Currently, nine research students are conducting their $\mathrm{PhD}$ in the HOAL. Based on the literature and previous work in the HOAL the students identify specific hypotheses within their research programmes. Typically, one hypothesis conforms to one research paper they are planning to prepare, but sometimes the hypotheses are more specific. The following steps 


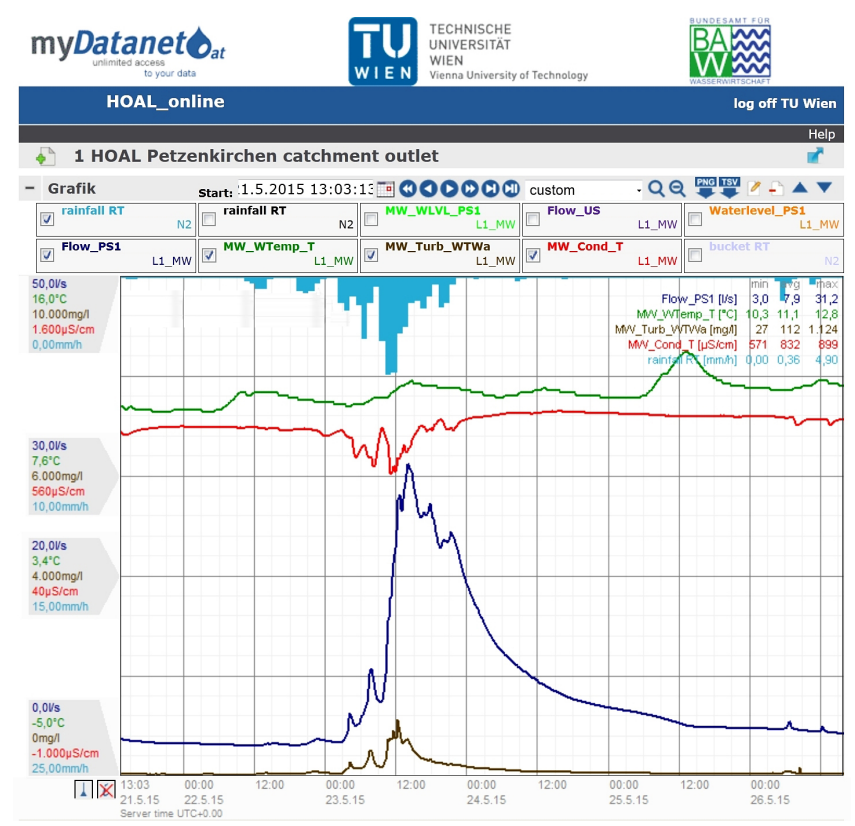

Figure 9. Screen shot of web-based real-time monitoring of the data collected in the HOAL.

were adopted in inferring the instrumentation or experimental set-up from the hypothesis to be tested.

- Background: importance of the research issue, prior knowledge of the issue and specific research question. In many instances the specific hypotheses are formulated and tested as a collaboration among students (joint science questions) building on previous work.

- Hypothesis: stating the hypothesis from knowledge of the processes in the literature and prior analyses in the catchment.

- Test: anticipating alternative test results and their implications for rejecting (or not rejecting) the hypothesis. If possible, more than one test is performed to test the same hypothesis, preferably based on different data and/or different rationales.

- Experiment: performing the experiment or the monitoring with required sensitivity.

- Outcomes: testing the hypothesis against the results of the experiment or the monitoring in the context of the assumptions involved and implications for the overarching science questions.

Below a number of examples of hypothesis testing are presented to illustrate the approach adopted in the HOAL. They relate to repeatable experiments (Example 1), temporal monitoring (Example 2), spatial monitoring (Example 3) and testing of instruments (Example 4). All of them use both basic (Sect. 3.2.1) and dedicated (Sect. 3.2.2) infrastructure.

\subsection{Example 1: what is the source of early stream sediment concentrations?}

- Background: understanding the sources of sediments is very relevant for managing contaminants such as phosphorus and for controlling soil loss from agricultural landscapes. During rainfall events, an early peak in the suspended sediment concentration is often observed (Eder et al., 2010). The sediments may either stem from erosion from hillslopes close to the stream or from reactivation of sediments on the stream bed that have been deposited during previous events. Observations of sediment concentrations during natural events are inconclusive, as sediment inputs may occur in a diffuse way along the stream which are difficult to measure. Alternative experiments are needed to test the origin of early suspended sediments in the stream.

- Hypothesis: early suspended sediment concentration peaks in the stream are a result of resuspension of sediments in the stream bed deposited during previous events, rather than a result of erosion from the catchment.

- Test 1: does sediment-free water pumped into the stream produce suspended sediment concentrations similar to those observed for natural events? Yes: cannot reject hypothesis. No: reject hypothesis.

- Test 2: do suspended sediment loads decrease for repeated experiments? Yes: cannot reject hypothesis. No: reject hypothesis.

- Experiment: two flushing experiments were conducted by pumping sediment-free water into the stream and measuring flow and sediment concentrations at three sites with high temporal resolution. The discharges were similar to those of early stages of natural events with comparable bed shear stresses.

- Outcomes: at the most upstream section (site 360) of the stream, significant sediment was resuspended from the stream bed with concentrations similar to those of natural events, so the first hypothesis was not rejected. Sediment concentrations and loads decreased along the stream as the flow velocities decreased as a result of the dispersion of the hydrograph (Fig. 10). During the second experiment the sediment load was much smaller than during the first experiment, so hypothesis 2 was not rejected either. This finding was interpreted as the result of the depletion of stream bed sediments during the first experiment. Comparison with natural events supported stream bed resuspension as the source of early sediment peaks. 


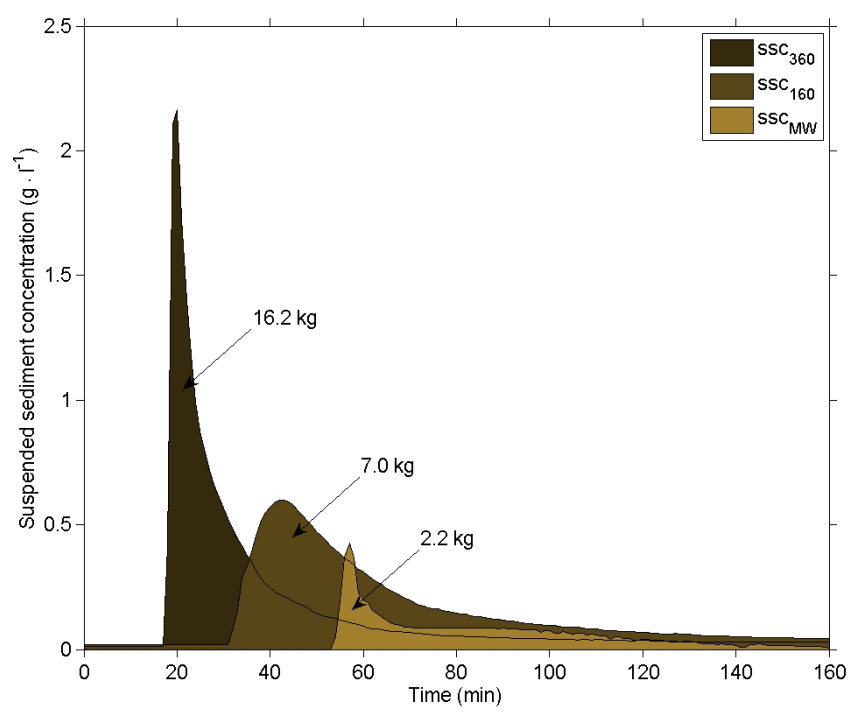

Figure 10. Hypothesis testing example 1: sediment concentrations for a flushing experiment in August 2011 at the three monitoring locations. 360 is the most upstream location at $360 \mathrm{~m}$ from the catchment outlet, MW. From Eder et al. (2014).

\subsection{Example 2: what are the sources and flow paths of event runoff?}

- Background: agricultural runoff into surface waters during rainfall events can originate from many different sources (e.g. multiple aquifers, unsaturated zone, event rainfall) and can take multiple interconnected flow paths (e.g. overland flow, macropore flow, matrix flow, tile drainage systems, etc.). Cost-effective mitigation measures of excess nutrients are harmful to the aquatic environment should be targeted on the sources and flow paths that conduct the bulk of the nutrient load rather than all sources and flow paths. Additionally, specific sources and flow paths may dominate during different periods within a runoff event throughout the entire length of the stream. Methods are needed to identify both sources and flow paths.

- Hypothesis: the shallow aquifer contributes the majority of the total discharge at MW during rainfall events.

- Test: does the shallow aquifer contribute less than 50\% to the total event discharge volume as compared to the event rain water and the unsaturated soil water? Yes: reject hypothesis. No: cannot reject hypothesis.

- Experiment: monitor discharge, chloride $(\mathrm{Cl})$ and nitrogen $(\mathrm{N})$ at $\mathrm{MW}$ over several years. Perform end-member mixing analysis (EMMA) based on the chemical signatures of the end-member reservoirs (i.e. event rainfall: low $\mathrm{Cl}$, low $\mathrm{N}$; soil water: medium $\mathrm{Cl}$, high $\mathrm{N}$; shallow aquifer: medium $\mathrm{Cl}$, medium $\mathrm{N}$ ) and assess the uncertainties.

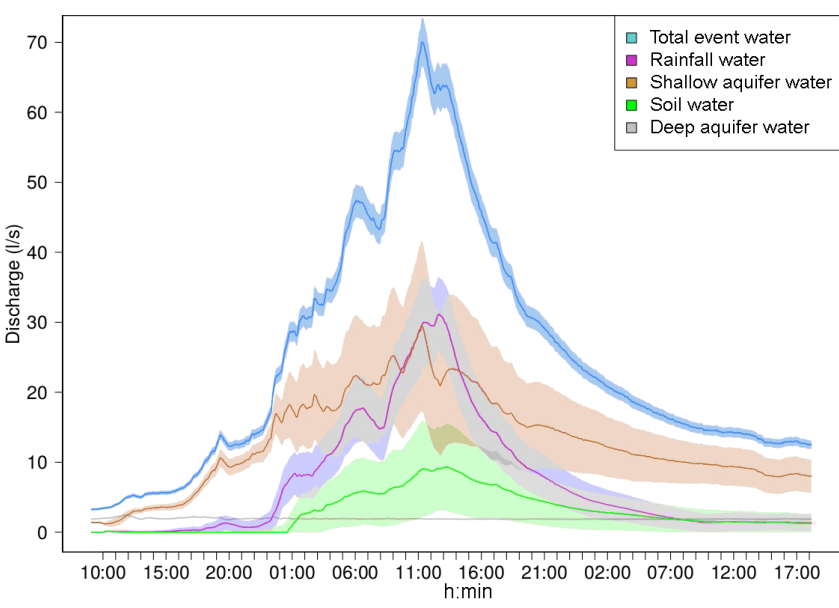

Figure 11. Hypothesis testing example 2: flow contributions for the event on 20 January 2012 at MW including uncertainties. Endmember mixing analysis (EMMA) was applied in a Monte Carlo mode with given error distributions on the concentrations and discharges which translate into the uncertainty distributions shown as shaded areas in the graph. See Exner-Kittridge et al. (2016) for details.

- Outcomes: EMMA suggests that, over the period 20112012 , the shallow aquifer contributes between $10 \%$ and $70 \%$ of the event discharge volume with an average of $45 \%$, depending on the event magnitude. During small to average events in summer, the shallow aquifer water dominates the total volume of the hydrograph, while the unsaturated soil water tends to contribute very little. Both preferential flow and pressure displacement appear to be the dominant pathways during these periods. During the winter months and events with high rainfall volumes, the contribution of unsaturated soil water and rain water can increase substantially (Fig. 11). This is attributed to high soil saturation conditions during these periods.

\subsection{Example 3: how do spatial soil moisture patterns change during rainfall events?}

- Background: understanding the controls of spatial soil moisture patterns in small catchments is essential for upscaling soil moisture from point to catchment scales and linking ground data to satellite data. The relative importance of the factors driving the spatial distribution of soil moisture was found to change during the season, e.g. topography may control the soil moisture distribution during wet periods, and vegetation and soil properties may be more dominant during dry conditions (Grayson et al., 1997). The changes in the patterns during rainfall events are less well documented and it has been hypothesised that the relative patterns remain 

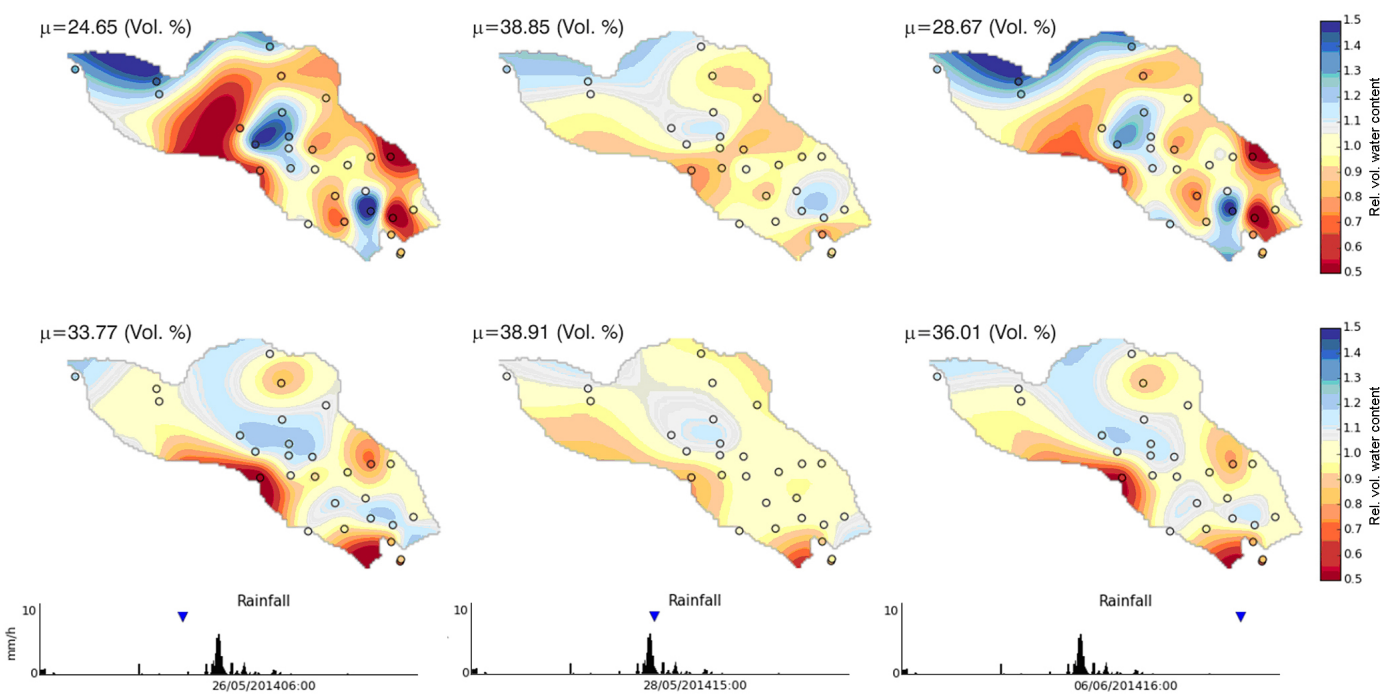

Figure 12. Hypothesis testing example 3: soil moisture patterns scaled by the mean catchment soil moisture $\mu$ before, during and after an event in May 2014. Top and bottom panels show 5 and $20 \mathrm{~cm}$ soil moisture, respectively. Circles show measurement locations, patterns are interpolations. Time series at the very bottom show rainfall with the time of the soil moisture patterns indicated by blue triangles.

stable (Grayson and Western, 1998). Observations are needed to test whether this is actually the case.

- Hypothesis: during spring rainfall events, the relative spatial soil moisture pattern remains stable throughout the events.

- Test: is a clear change in relative soil moisture patterns observable over the catchment? Yes: reject hypothesis. No: cannot reject hypothesis.

- Experiment: soil moisture was monitored at many locations within the catchment before, during and after a large rain event.

- Outcomes: the spatial patterns do change during the rainfall event examined in this particular catchment, both at 5 and $20 \mathrm{~cm}$ depth (Figure 12), so the hypothesis is rejected. Relative soil moisture is more evenly distributed during the event than before, although the centre and the north-eastern part of the catchment are consistently wetter. After the event the soil dries out and the patterns return to a similar state as before the event. The main difference in the patterns is their variance, so a different scaling (rather than by the spatial mean) may produce greater similarity. On the other hand, one would expect bigger changes than those in Fig. 12 for drier antecedent soil moisture as is typical of summer events.

\subsection{Example 4: can faecal indicators be consistently monitored on an on-line basis?}

- Background: on-line detection of enzymatic beta-DGlucurondiase (GLUC) activity has been suggested as a potential surrogate for microbiological faecal pollution monitoring with a capacity for near-real-time applications in the context of water safety management (Farnleitner et al., 2001, 2002). Such measurements will also allow shedding of light on microbial transport processes at the catchment scale. While automated measuring devices have already been tested for groundwater (Ryzinska-Paier et al., 2014), so far no evaluation exists for surface water. Surface water may involve additional challenges due to higher sediment concentrations and bacterial contamination levels which may contaminate or block inlet pipes and other system components. The HOAL is an ideal test bed for the method due to its highly dynamic runoff, sediment concentrations and bacterial contamination. Devices with two different designs (BACTcontrol and ColiMinder) are available in the HOAL (Stadler et al., 2016).

- Hypothesis: GLUC activity in surface water can be consistently measured by devices differing in construction (consistent meaning $R^{2}>0.9$ and $p$ value $<0.001$ ).

- Test 1: are measurements of devices with identical constructions consistent? Yes: cannot reject hypothesis. No: reject hypothesis.

- Test 2: are measurements of devices with different constructions consistent? Yes: cannot reject hypothesis. No: reject hypothesis.

- Experiment: four devices for automated GLUC measurements were installed at the catchment outlet and operated in parallel for a period of 12 months (two sets of two identical devices, BACTcontrol and ColiMinder). 

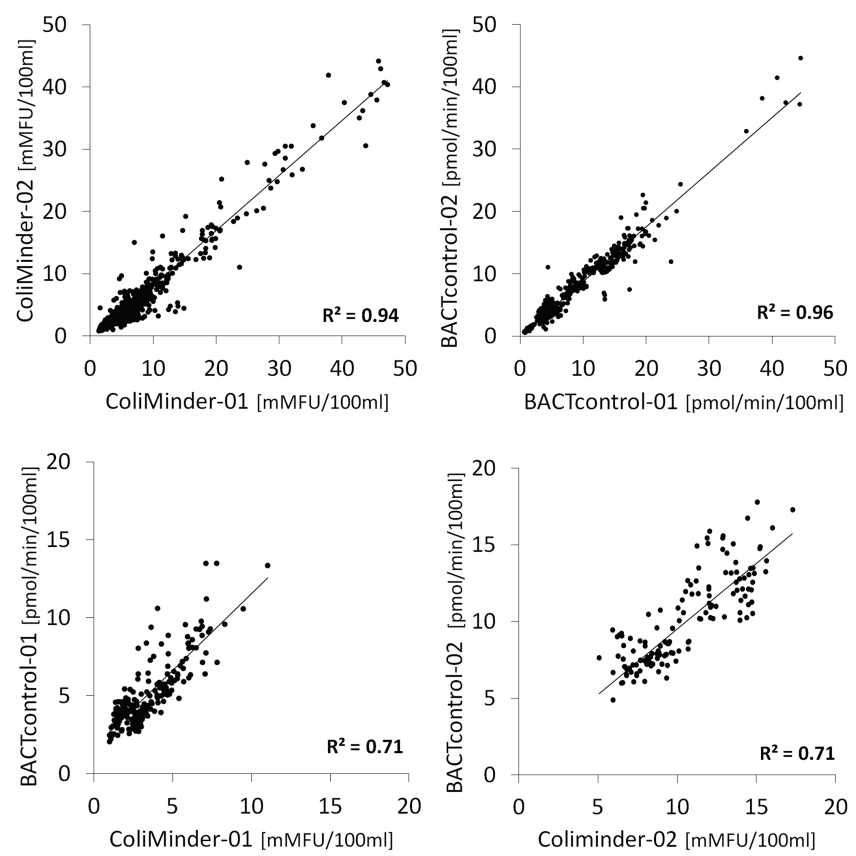

Figure 13. Hypothesis testing example 4: consistency of online monitoring of microbial faecal pollution by GLUC activity as a surrogate. Top panels (Test 1) compare devices with the same design and assay (BACTcontrol vs. BACTcontrol, ColiMinder vs. ColiMinder). Bottom panels (Test 2) compare devices with different designs and assays (BACTcontrol vs. ColiMinder). The smaller range of the bottom panels is related to differences in the measurement period. All correlations are significant at $p$ values $<0.001$. See Stadler et al. (2016) for details.

- Outcomes: results from Test 1 (Fig. 13, top) show that devices with identical constructions are indeed extremely consistent $\left(R^{2}>0.9\right)$. Test 2 (Fig. 13, bottom), however, shows that different designs lead to less consistent results $\left(R^{2}=0.71\right)$, so hypothesis 2 was rejected. The lower correlations in the latter case are mainly due to the different designs and partly related to slightly different intake locations (about $2 \mathrm{~m}$ separation) and measurement times (up to $60 \mathrm{~min}$ time offset). Overall, the experiments suggest that the instruments are indeed useful for near-real-time monitoring of GLUC activity.

\section{Lessons learned and outlook}

\subsection{Lessons regarding science strategy of the HOAL}

\subsubsection{Long-term experimental infrastructure}

The research since the inception of the HOAL has demonstrated that the strategy of base monitoring related to overarching science questions and dedicated monitoring related to specific hypotheses indeed works well. Substantial synergies were realised between the dissertation studies that shared the base monitoring. For example, most students used the runoff measurements at high temporal and spatial resolution in the context of their own specific science questions such as runoff generation, flow paths, nutrient budgeting, sediment transport and evaporation estimation. On the other hand, the dedicated monitoring allowed collection of exactly the information needed to test specific hypotheses and thus maximise the efficiency of the HOAL. Two generations of research students have so far worked in the HOAL. The overall, structured set-up geared towards long-term research assisted students in building on the findings of the previous generation. When students left, there was sufficient expertise among the team members for a smooth transition to new students. Practical aspects such as the HOAL manager and the web logbook turned out to be valuable in this transition.

\subsubsection{Interdisciplinary collaboration}

Interdisciplinarity is both a consequence of the type of societally relevant research questions being addressed in the HOAL, and it also provides an opportunity to address more complex research questions than would be possible by researchers from only one discipline. Students have clearly recognised that through collaboration with others they are able to gain knowledge and understanding that enables them to delve deeper into their own research topic (see Carr et al., 2015). Additionally, they often also see immediate benefits to their collaboration in the form of a data set, which provides further motivations for continuing to work collaboratively. However, they also recognised that collaboration across the disciplines can bring additional challenges as time and effort is needed to understand and incorporate knowledge from other research fields. Study sites, such as the HOAL, provide a focal point where researchers from different disciplines can interact, develop joint hypotheses together and work collaboratively on data collection or experimentation. As such, this can be seen to raise the efficiency of interdisciplinary collaboration because research students have greater clarity on who and why they need to collaborate with to overcome specific research challenges in answering their joint research questions.

\subsubsection{Networking within the science community and beyond}

The collaboration between TU Wien and IKT fully realised the potential of the complementary expertise. Similarly, collaboration with some of the providers of the instrumentation turned out to be very useful and allowed science questions to be addressed (e.g. comparative testing of monitoring microbial pollution proxies) that would be difficult to address otherwise. Collaborations with other research institutions sometimes posed an issue regarding the time axes. Joint projects usually turned out to take longer (and consume more re- 
sources) than anticipated. The joint projects were not always the top priority of the project partners which added to delays. A more rigorous planning of joint projects in the future, including set deadlines, deliverables and clear budgets, may help increase the efficiency of such activities. Communication and outreach activities were received well, although there is probably potential for additional activities from local to global scales.

\subsection{Lessons regarding implementation}

\subsubsection{Site selection and hydrological characteristics}

The HOAL site turned out to be an excellent choice for the same reasons it was selected in the first place. The different runoff generation mechanisms indeed allowed some very interesting and unique hypothesis testing associated with flow paths and water sources. The proximity of the HOAL to the Institute for Land and Water Management Research was probably one of the most fortunate choices of the entire project. The logistic benefits for maintenance and connection to the power grid and high-speed glassfibre LAN turned out to be immense. This is certainly an important lesson learned and we can warmly recommend a similar set-up for other hydrological laboratories.

\subsubsection{Setting up the HOAL and instrumentation}

While the overall science strategy and site selection clearly worked well, the implementation of the instrumentation was not always easy. All instrumentation was finally installed and functional in a similar way as planned but, on the way, there were considerable challenges, even though there was substantial expertise within the team members with field experimentation. With the benefit of hindsight the HOAL team would probably approach some of the installations differently.

Challenges with the flumes: H-flumes were planned for runoff measurements for some of the tributaries within the HOAL. The main motivation for choosing H-flumes over V-notch weirs was the hope that they will be less prone to siltation although, ultimately, siltation was not completely avoided. The choice of H-flumes came at a cost of lower measurement accuracy at low flows. Initially the main scientific interest was on large floods, but soon it became clear that the entire runoff spectrum is of interest. Additionally, the H-flumes were overdesigned. This was partly due to the early focus on floods and partly due to internal communication issues where each of the team members added a "safety margin" to the maximum design flow to ensure that it is never exceeded. Finally, for simplicity only three size classes were constructed and in this step most flumes were additional increased to fit a class. After a year, when the problems became evident, the cross sections of the flumes were narrowed down to improve their accuracy and tipping buckets were added, but the lesson learned is that some extra time and coordination in the initial planning of the flumes would probably have paid off.

Another problem with the flumes was freezing in winter. In the first winter, the team lost a number of pressure transducers (although the same make had worked fine during winter in a different catchment). Later, a heating system was installed and the flumes were insulated but freezing remains a problem in some situations. It was not always easy to seal the flumes to the ground because of erosion processes and leakage occurred repeatedly. One of the practical fixes were lateral metal sheets attached to the flumes and dug into the ground. Regular maintenance is needed to ensure that no leakage occurs. Finally, the positions of the pressure transducer changed due to the technical interventions. Regular checking of the positions and manual discharge measurements on a weekly basis for quality assurance purposes were found to be very important.

Similarly, operation of the soil moisture sensor network turned out to be more time consuming than anticipated. Part of the problem is the agricultural use of the HOAL requires temporary sensors to be removed and replaced once or twice a year in accordance with the agricultural manipulations on the fields. When replacing the sensors that soil profile had obviously been disturbed, so some of the continuity of the measurements was lost. Forested catchments (Bogena et al., 2010) or pastures (Western et al., 1999) would allow more straightforward instrumentation and more consistent soil moisture data. There were also leakage issues with the housing of the equipment, and the sensors were not always straightforward to calibrate. Clearly, soil moisture sensing needs utmost care in order to obtain accurate results.

Overall, there were a range of setbacks which is not surprising given the enormous number of sensors installed in the HOAL, a total of more than 300, in addition to sampling, experiments and surveys. Much of the research focused on high spatial detail which, in many instances, was realised by a large number of sensors at different locations, but any sensor failures during limited periods of time translated to missing data and reduced spatial detail. Other issues included faulty parts of the instruments, faulty software updates and damage to the glass fibre cable during construction of a nearby building. Additionally, compatibility between different sensorsdata-logger systems was not always straightforward, for example due to different preset measurement intervals. The lesson learned is that such issues are difficult to avoid and it is important to be flexible and vigilant. A dedicated person (the HOAL manager) responsible for the overall management certainly turned out to be very valuable in minimising the loss of data and maximising their accuracy.

On the other hand, there were a number of things that worked better than anticipated. One of them is the web access to the data in real time, which allows an online-check of the measurements. There were numerous instances where measurement or connectivity problems were quickly identified 
and repaired. The web access also allows changing the sampling discs of the autosampler when needed and to control the sampling intervals remotely according to the current weather and streamflow conditions, which turned out to be useful. Permanent electrical supply throughout the entire length of the stream was a great benefit for the easy installation, testing, and long-term monitoring of equipment. Without a permanent power supply, certain types of equipment would have not been possible to have been installed, while others would have been very difficult to maintain.

\subsubsection{Managing the HOAL}

The HOAL manager position was filled in early 2013 and the benefits of a manager quickly became apparent. Previously, communication with the landowners was complicated as there was no single contact point of the HOAL team. Yet, a good system of co-operation is necessary for the installation and operation of instrumentation such as tripod-mounted eddy-covariance devices and the soil moisture sensors. The addition of the HOAL manager position to the project had a very positive effect on this process. With the manager recruited from the locality, communication with the landowners was now immediate, as was seen for example from the planning of an evaporation field campaign, as the manager works directly with the research students on a daily basis and hence has detailed knowledge of their research, much more effective and efficient than previously. A good working relationship with the landowners was facilitated by sharing some of the findings of the HOAL, e.g. on erosion sources and potential protection measures, groundwater protection, and fertiliser management, as well as on the weather data.

Similarly, the manager was invaluable for coordinating the maintenance. The implementation of a weekly maintenance plan by the manager ensured that no important work was overlooked. The plan also facilitated the communication between the group members, e.g. when research students were on temporary leave during their research semester abroad. Similarly the web-logbook was instrumental in maximising data quality and ensuring a realistic interpretation of the data. On the other hand, the maintenance turned out to be quite time consuming. For example, the cleaning of the $\mathrm{H}$-flumes at the stream tributaries consumes considerable time resources. Additional maintenance is needed to clean out dead leaves in autumn. Maintenance works also involves mowing the grass around the instrumentation to avoid shading of solar panels. The soil moisture network required substantial maintenance, in particular the end devices buried a few centimetres below ground, which tended to get wet and had to be cleaned.

The main advantages of this iterative, network-based process of conducting hypothesis testing are its flexibility and the encouragement of creative thinking by the students. There were a number of instances where this flexibility allowed exploiting collaborative opportunities. Examples in- clude a field campaign on identifying the relative contributions of transpiration and soil evaporation together with the IAEA and the validation of NASA's SMAP satellite based on soil moisture data in the HOAL.

At the beginning of the project, the data management was not an easy process. The main challenge were in organising and checking data from a large number of different sensors, communication and a consistent protocol between all the people involved. The raw data correction process consumed more resources than anticipated. Eventually, the overall data management approach did run smoothly. Regular backups and simple and robust data formats (such as the csv file format) for flexible data exchange proved to be useful.

\subsection{Lessons regarding hypothesis testing}

The general philosophy of a hypothesis-based observatory was considered by the HOAL team members to work well. The hypotheses provided guidance for the dedicated monitoring and experimentation and they facilitated the transformation of the research findings into publications. In particular, thinking in terms of hypotheses was found to be useful, as it is directly linked to the research questions addressed in individual papers.

However, hypothesis testing was not always as clear-cut as one would hope (Chamberlin, 1965; Srinivasan et al., 2015). There were two issues which were related to (a) setting up the hypothesis and (b) the outcomes of the hypothesis testing.

(a) Setting up of the hypothesis: setting up of the hypothesis was constrained by the available resources. Once equipment had been purchased, other hypotheses were also constrained by the available infrastructure. One of the issues is the sensitivity of the measurements with respect to the hypothesis. For example, soil moisture sensor pairs installed in the field at the same location gave very consistent results but comparisons with the gravimetric method (oven-drying of samples) did not. The main difficulty was the small sampling volume of the sensors and the immense spatial soil moisture variability, particularly near the surface due to burrows, roots, cracks and soil characteristics. Additional site-specific calibration of any soil moisture sensor prior to installation turned out to be essential. It is hence not clear how sensitive the soil moisture network is to catchment-scale hypotheses. In the near future, validation will be based on a portable TDR sensor with a sampling volume similar to that of the sensors. In a similar vein, the observations of the saturation and/or overland flow patterns by video monitoring were focussed on a particular 2 ha area that is usually cultivated with maize or winter wheat. With young crops the patterns can be clearly observed but later in the season this is no longer possible. However, since the field patches are cultivated at different times, it is possible to switch the observation area to an alternative bare patch to maximise the period of pattern observations within the HOAL. To decide about the best patches, prior planning is needed. 
Clearly, the more complex the processes are, the more difficult it is to set up clear-cut hypotheses (see e.g. Reischer et al., 2011, for a complex case). As Knorr-Cetina (2013, 4-5) noted, "the products of science are contextually specific constructions which bear the mark of the situational contingency and interest structure of the process by which they are generated,", and "If there is a principle which seems to govern laboratory action, it is the scientists' concern with making things "work", which points to a principle of success rather than one of truth. [...] Thus, it is success in making things work which is reinforced as a concrete and feasible goal of scientific action, and not the distant ideal of truth which is never quite attained." It is therefore clear that the outcomes of the hypothesis testing will not be independent of the preconceptions and interests of all those involved. Holländer et al. (2014) illustrates this notion for the more specific case of hydrological predictions.

Some of the examples in this paper do illustrate the difficulty with reducing complex science questions to hypotheses with binary outcomes. Hypothesis example 2 in this paper is quite specific, while a more relevant question would perhaps enquire about the causal mechanisms driving the sources and flow paths of event runoff. Similarly, one is usually more interested in the more complex questions of the mechanisms driving spatial soil moisture patterns rather than simply whether they change during events or not (example 3 ). The issue of complex process interactions that cannot be easily disentangled by individual hypotheses permeates much of hydrology, similar to the non-repeatability of experiments. More work on framing relevant and yet testable hypotheses in hydrology is needed (Sivapalan, 2009).

(b) Outcomes of the hypothesis testing: the second issue was that the outcomes of the hypothesis testing were not always fully conclusive. This is illustrated by the four examples, where rejection (or non-rejection) of the hypothesis was usually associated with some qualifications. Perhaps more importantly, the issue is that, with the exception of a few repeatable experiments performed in the HOAL (such as example 1), most testing was not repeatable due to the randomness in weather and other boundary and initial conditions which cannot be fully specified (Zehe and Blöschl, 2004; Zehe et al., 2007). The lack of repeatability of experiments and the associated limits to predictability (Blöschl and Zehe, 2005) are a real issue in hydrology. Ideally, one would like to have at least three replicas of the same experiments. There are a few examples where this is already put into practice, such as the Biosphere 2 hillslope experiments performed in a green house (Hopp et al., 2009) but, usually, even dedicated largescale experiments such as the Chicken Creek artificial catchment (Holländer et al., 2009, 2014) do not involve multiple replicas.

A similar question that arises is how representative the HOAL of other (experimental or larger) catchments around the world is, i.e. the question of whether and how the findings of the HOAL can be generalised. The diversity of runoff gen- eration processes encountered in the HOAL is considered instrumental in making the findings more generally applicable to a variety of agricultural catchment settings. The students are forced from the beginning of their $\mathrm{PhD}$ projects to carefully think about, formulate and interpret their experiments with respect to such broader settings. On the other hand, care needs to be taken in building models that are based on the specifics of the HOAL.

Notwithstanding these caveats related to hypothesis testing, experiences in the HOAL also showed that there were a number of unforeseen opportunities to test hypotheses and acquire knowledge that were not anticipated, i.e. positive surprises. Some of them occurred through collaborations with partners. The HOAL has been shown to numerous guest scientists, it has been used for field training during the Meeting of the European Geosciences Union and it is used as a site for TU Wien courses on field work. Unexpected opportunities that arose from these collaborations were a field campaign on separating transpiration and bare soil evaporation based on isotopic measurements, operated in collaboration with the International Atomic Energy Agency (IAEA) in June 2014. A Picarro isotope analyser system was installed in the field and both institutions benefited from the shared expertise during this field test.

Another example of an unforeseen opportunity was an unplanned, yet very interesting observation in February 2015 when the research students conducted field work to sample stream water quality to test hypotheses regarding diurnal fluctuations relative to summer conditions. A period without snow and rain was selected to ensure no surface water input into the stream. As it turned out, temperatures rose slight above zero which melted frozen soil water in the catchment and produced a quite significant discharge into the stream, more than doubling streamflow. The event was neither rain nor snowmelt driven, which is not commonly observed. The comprehensive instrumentation in the HOAL allowed a detailed analysis of the hydrological situation of this interesting event. It was speculated that such mechanisms may occur more often than usually assumed, yet they are rarely considered in rainfall runoff models.

\subsection{Outlook}

The ambition of the Hydrological Open Air Laboratory (HOAL) in Petzenkirchen is to advance the understanding of water-related flow and transport processes involving sediments, nutrients and microbes in small catchments. Overall, the concept of long-term facilities that transcend the lifetime of individual projects, a commitment to interdisciplinary research, and the involvement in networks to assist in performing collaborative science has worked well so far.

Two generations of research students have so far pursued research in the HOAL. The third generation of students will address issues of upscaling and hydrological change. The fourth generation of students will be concerned with how all 
of these findings can be generalised to other climatic and management conditions around the world. More extensive collaborations will allow addressing a wider range of science questions and realise the full potential of an important network within the scientific community. Future societal water challenges revolve around sustainable water management in a changing world (Leibundgut et al., 2014). Hydrological change, hydrological and microbial risks, nutrients and emerging substances are all issues that will likely increase in importance in the near future. Innovative technology and approaches for better understanding water-related processes in the environment are needed. There are numerous opportunities to further develop new technology (e.g. new tracers, sensors, protocols) in the framework of the HOAL to address some of the knowledge gaps and issues discussed above.

This paper has focused on the scientific and implementation aspects of the HOAL. There are also financial aspects that are fundamental to the safe operation of the laboratory. Currently, much of the funding comes from the Austrian Sciences Funds, the TU Wien and the Federal Agency for Water Management. As the activities branch out to a larger number of collaboration partners, care needs to be taken to ensure the long-term funding of the Hydrological Open Air Laboratory.
The HOAL is becoming a hub for hosting guest scientists, through a closely knit network with other academic institutions and observatories. The HOAL is special in that many runoff generation processes (surface runoff, spring runoff, tile drainage, runoff from wetlands) can be observed simultaneously and at the high spatial and temporal resolution with which the processes are monitored. This particular profile opens exciting opportunities for complementary, comparative research with different hydrological observatories and experimental catchments in different environments (e.g. Schumann et al., 2010) to foster progress in the interdisciplinary water sciences. 


\section{Appendix A: Catchment details}

Table A1. Catchment details.

\begin{tabular}{|c|c|}
\hline Location & $\begin{array}{l}\text { Near Petzenkirchen, in the western part of Lower Austria } \\
\text { Weather station: } 48^{\circ} 09^{\prime} 17.7^{\prime \prime} \mathrm{N}, 15^{\circ} 08^{\prime} 54.0^{\prime \prime} \mathrm{E} \\
\text { Catchment outlet: } 48^{\circ} 09^{\prime} 00.9^{\prime \prime} \mathrm{N}, 15^{\circ} 09^{\prime} 10.9^{\prime \prime} \mathrm{E}\end{array}$ \\
\hline Catchment size: & 65.8 ha. \\
\hline \multirow[t]{4}{*}{ Climate and runoff: } & $\begin{array}{l}\text { Mean annual air temperature (1990-2014): } 9.5^{\circ} \mathrm{C} \\
\text { Range (1990-2014): } 7.9^{\circ} \mathrm{C}(1996) \text { to } 10.6{ }^{\circ} \mathrm{C}(1994) \\
\text { Mean monthly air temperature }(1990-2014) \text { : Jan }-0.4{ }^{\circ} \mathrm{C} \text {, Feb } 0.9^{\circ} \mathrm{C} \text {, Mar } 5.1^{\circ} \mathrm{C}, \text { Apr } 9.6^{\circ} \mathrm{C} \text {, } \\
\text { May } 14.3^{\circ} \mathrm{C} \text {, Jun } 17.4^{\circ} \mathrm{C} \text {, Jul } 19.2^{\circ} \mathrm{C} \text {, Aug } 18.9^{\circ} \mathrm{C} \text {, Sep } 14.3^{\circ} \mathrm{C} \text {, Oct } 9.4^{\circ} \mathrm{C} \text {, Nov } 4.4^{\circ} \mathrm{C} \text {, Dec } \\
0.0^{\circ} \mathrm{C}\end{array}$ \\
\hline & $\begin{array}{l}\text { Mean annual precipitation (1990-2014): } 823 \mathrm{~mm} \mathrm{yr}^{-1} \\
\text { Range (1990-2014): } 591 \mathrm{~mm} \mathrm{yr}^{-1} \text { (2003) to } 1090 \mathrm{~mm} \mathrm{yr}^{-1}(2002) \\
\text { Mean monthly precipitation }(1990-2014): \text { Jan } 48.7 \mathrm{~mm} \text {, Feb } 46.7 \mathrm{~mm} \text {, Mar } 64.9 \mathrm{~mm} \text {, Apr } \\
50.0 \mathrm{~mm} \text {, May } 78.4 \mathrm{~mm} \text {, Jun } 99.4 \mathrm{~mm} \text {, Jul } 89.5 \mathrm{~mm} \text {, Aug } 95.5 \mathrm{~mm} \text {, Sep } 79.6 \mathrm{~mm} \text {, Oct } 54.8 \mathrm{~mm} \text {, } \\
\text { Nov } 62.4 \mathrm{~mm} \text {, Dec } 53.6 \mathrm{~mm}\end{array}$ \\
\hline & Mean catchment evaporation (1990-2014) based on the water balance: $628 \mathrm{~mm} \mathrm{yr}^{-1}$ \\
\hline & 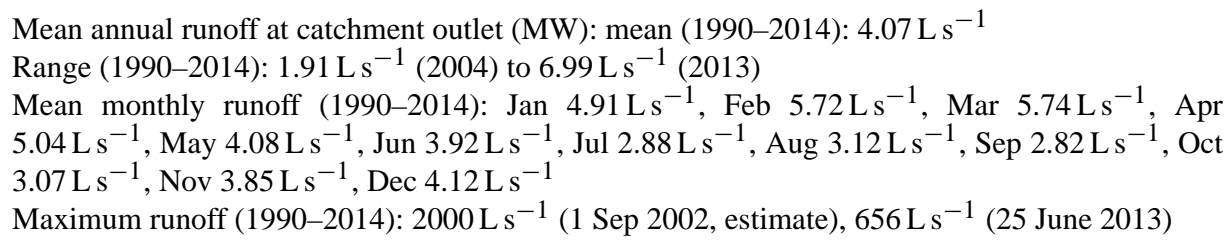 \\
\hline Soils: & $\begin{array}{l}\text { The soil types are Cambisols }(56 \%) \text {, Planosols }(21 \%) \text {, Anthrosols }(17 \%) \text {, Gleysols }(6 \%) \text { and } \\
\text { Histosols }(<1 \%) \text {. Infiltration capacities tend to be medium to low, water storage capacities tend } \\
\text { to be high, and shrinking cracks may occur in summer due to high clay contents. }\end{array}$ \\
\hline Geology and aquifers: & $\begin{array}{l}\text { The subsoil consists of Tertiary sediments of the Molasse zone and fractured siltstone. The shallow } \\
\text { aquifer is associated with the water draining the shallow subsurface soil, while the deep aquifer is } \\
\text { within the fractured siltstone unit. }\end{array}$ \\
\hline Topography: & $\begin{array}{l}\text { Elevation range: } 268 \text { to } 323 \mathrm{~m} \text { a.s.l. } \\
\text { Mean slope: } 8 \% \text {. }\end{array}$ \\
\hline Vegetation/land use: & $\begin{array}{l}\text { At present, } 87 \% \text { of the catchment area is arable land, } 5 \% \text { is used as pasture, } 6 \% \text { is forested and } \\
2 \% \text { is paved. The crops are mainly maize, winter wheat, rape and barley. }\end{array}$ \\
\hline Fertiliser input: & $\begin{array}{l}\text { Nitrogen fertiliser input (2010-2013, catchment average): Range } 140 \mathrm{~kg} \mathrm{Nha}^{-1} \text { (2013) to } \\
210 \mathrm{~kg} \mathrm{~N} \mathrm{ha}^{-1}(2012) \\
\text { Phosphorus fertiliser input (2010-2013, catchment average): Range } 12 \mathrm{~kg} \mathrm{Pha} \mathrm{(2013)} \mathrm{to} 26 \mathrm{~kg} \mathrm{P} \text { ha } \\
\text { (2012) }\end{array}$ \\
\hline Seitengraben stream: & $\begin{array}{l}\text { Length: } 620 \mathrm{~m} \text {, slightly meandering } \\
\text { Continuous shaded by deciduous trees and bushes in riparian zone. } \\
\text { Biologically active ecosystem with small water animals and plants. } \\
\text { Discharges into Hauptgraben river which discharges into the Erlauf and finally the Danube). }\end{array}$ \\
\hline
\end{tabular}




\section{Appendix B: Instrumentation}

Table B1. Instrumentation in the HOAL. Compartments (Comp): GW = groundwater, $\mathrm{SW}=$ surface water, A= atmosphere. Location: $\mathrm{MW}=$ catchment outlet, WS $=$ Weather station (also see Figs. 6 and 7). Data connectivity: LAN = glassfibre LAN, M= local storage and manual data transfer, $\mathrm{P}=\mathrm{GSM}$ phone, $\mathrm{S}=$ satellite modem. Main data storage: $\mathrm{Cosmos}=\mathrm{Cosmos}$ project server, $\mathrm{HP}=\mathrm{HOAL} \mathrm{PC}$, $\mathrm{IKT}=\mathrm{IKT}$ server (plain file system), MN $=\mathrm{IKT}$ server (MydataNet), Soil $=$ Soil Net PC, TU $=\mathrm{TU}$ server, VWM $=\mathrm{VWM}$ server.

\begin{tabular}{|c|c|c|c|c|c|c|c|c|c|c|}
\hline Variable & Units & Comp. & $\begin{array}{l}\text { No. of } \\
\text { stations } \times \\
\text { sensors }\end{array}$ & Location & Sensor & Sensor type & $\begin{array}{l}\text { Temporal } \\
\text { resolution } \\
\text { (min) }\end{array}$ & $\begin{array}{l}\text { Data } \\
\text { connectivity }\end{array}$ & $\begin{array}{l}\text { Main data } \\
\text { storage }\end{array}$ & $\begin{array}{l}\text { Data from } \\
\text { (year) }\end{array}$ \\
\hline Precipitation & $\mathrm{mm} \min ^{-1}$ & A & 4 & Catchment & Precipitation gauge & OTT Pluvio & 1 & $\mathrm{P}$ & MN & 2010 \\
\hline Air temperature & ${ }^{\circ} \mathrm{C}$ & A & $1 \times 3$ & WS & Temperature sensor at $2,5,10 \mathrm{~m}$ & HMP 155 & 30 & LAN & $\mathrm{HP}$ & 2012 \\
\hline Air humidity & $\%$ & A & $1 \times 3$ & WS & Humidity sensor at $2,5,10 \mathrm{~m}$ & HMP 155 & 30 & LAN & $\mathrm{HP}$ & 2012 \\
\hline Wind speed and direction & $\mathrm{ms}^{-1},{ }^{\circ}$ & A & $1 \times 3$ & WS & Wind sensor at $2,5,10 \mathrm{~m}$ & $\begin{array}{l}\text { Gill Wind- } \\
\text { Sonic }\end{array}$ & 30 & LAN & $\mathrm{HP}$ & 2012 \\
\hline Atmospheric pressure & $\mathrm{hPa}$ & A & 1 & WS & Barometer & EC100 & 1 & LAN & $\mathrm{HP}$ & 2012 \\
\hline $\begin{array}{l}\text { Radiation (incoming short-wave, } \\
\text { incoming long-wave, outgoing } \\
\text { short-wave, outgoing long-wave) }\end{array}$ & $\mathrm{Wm}^{-2}$ & A & $1 \times 4$ & WS & Four-component net radiometer & $\begin{array}{l}\text { Kipp \& Zo- } \\
\text { nen CNR } 4\end{array}$ & 1 & LAN & $\mathrm{HP}$ & 2012 \\
\hline $\begin{array}{l}\text { Raindrop distribution, air temper- } \\
\text { ature, relative humidity }\end{array}$ & $\begin{array}{l}\text { Number of drops, } \\
{ }^{\circ} \mathrm{C}, \%\end{array}$ & A & $1 \times 3$ & WS & Present weather sensor at $1.7 \mathrm{~m}$ & $\begin{array}{l}\text { Campbell } \\
\text { PWS } 100\end{array}$ & 1 & LAN & $\mathrm{HP}$ & 2012 \\
\hline $\begin{array}{l}\text { Carbon dioxide flux, latent heat } \\
\text { flux, sensible heat flux, momen- } \\
\text { tum flux }\end{array}$ & $\begin{array}{l}\mathrm{mmol} \mathrm{m}^{-2} \mathrm{~s}^{-1}, \\
\mathrm{~W} \mathrm{~m}^{-2}, \\
\mathrm{~W} \mathrm{~m}^{-2}, \\
\mathrm{~kg} \mathrm{~m}^{-1} \mathrm{~s}^{-2}\end{array}$ & A & 2 & $\begin{array}{l}\text { Catchment } \\
\text { (movable device) }\end{array}$ & $\begin{array}{l}\text { Open-path eddy covariance (3-D } \\
\text { wind speed, water vapour, carbon } \\
\text { dioxide density) }\end{array}$ & $\begin{array}{l}\text { Campbell IR- } \\
\text { GASON }\end{array}$ & $\begin{array}{l}10 \mathrm{~Hz}, 30 \mathrm{~min} \\
\text { aggregation }\end{array}$ & M & $\mathrm{HP}$ & $2012 / 2013$ \\
\hline $\begin{array}{l}\text { Carbon dioxide flux, latent heat } \\
\text { flux, sensible heat flux, momen- } \\
\text { tum flux }\end{array}$ & $\begin{array}{l}\mathrm{mmol} \mathrm{m}^{-2} \mathrm{~s}^{-1}, \\
\mathrm{~W} \mathrm{~m}^{-2}, \\
\mathrm{~W} \mathrm{~m}^{-2}, \\
\mathrm{~kg} \mathrm{~m}^{-1} \mathrm{~s}^{-2}\end{array}$ & A & 1 & WS & $\begin{array}{l}\text { Closed-path eddy covariance } \\
\text { (3-D wind speed, water vapour, } \\
\text { carbon dioxide mixing ratio) }\end{array}$ & $\begin{array}{l}\text { Campbell } \\
\text { EC155 }\end{array}$ & $\begin{array}{l}10 \mathrm{~Hz}, 30 \mathrm{~min} \\
\text { aggregation }\end{array}$ & M & HP & 2013 \\
\hline Momentum and sensible heat flux & $\mathrm{Wm}^{-2}$ & A & 1 & $\begin{array}{l}\text { Catchment } \\
\text { (movable device) }\end{array}$ & Scintillometer & $\begin{array}{l}\text { Scintec SLS- } \\
20\end{array}$ & 1 & LAN & $\mathrm{HP}$ & 2012 \\
\hline Wind load (acceleration) & $\mathrm{ms}^{-2}$ & A & $1 \times 7$ & WS & Triaxial DC Accelerometer & $\begin{array}{l}\text { 3713B1110G, } \\
\text { MEMS Ca- } \\
\text { pacitive }\end{array}$ & $100 \mathrm{~Hz}$ & M & HP & 2015 \\
\hline Snow depth & $\mathrm{m}$ & Surface & 1 & WS & Snow depth US sensor & SR50AT & 1 & LAN & $\mathrm{HP}$ & 2012 \\
\hline $\begin{array}{l}\text { Saturation patterns on land } \\
\text { surface }\end{array}$ & - & Surface & 1 & WS & $\begin{array}{l}\text { Camera, timelapse pictures, } \\
\text { recorded video (on detected } \\
\text { motion) }\end{array}$ & $\begin{array}{l}\text { Sanyo VCC- } \\
\text { MCH5600P }\end{array}$ & 1 & LAN & $\mathrm{HP}$ & 2013 \\
\hline Discharge & $\mathrm{Ls}^{-1}$ & SW & 1 & $\begin{array}{l}\text { Sys4 (inlet, piped } \\
\text { stream) }\end{array}$ & $\begin{array}{l}\text { H-flume, pressure transducer } \\
\text { (water level) }\end{array}$ & $\begin{array}{l}\text { Druck } \\
\text { PTX1830 }\end{array}$ & 1 & LAN & MN & 2011 \\
\hline $\begin{array}{l}\text { Electrical conductivity } \\
\text { and water temperature }\end{array}$ & $\mu \mathrm{S} \mathrm{cm}^{-1},{ }^{\circ} \mathrm{C}$ & SW & $1 \times 2$ & $\begin{array}{l}\text { Sys4 (inlet, piped } \\
\text { stream) }\end{array}$ & Electric conductivity probe & $\begin{array}{l}\text { WTW } \\
\text { TetraCon }\end{array}$ & 1 & LAN & MN & 2011 \\
\hline $\mathrm{pH}, \mathrm{Cl}, \mathrm{NO}_{3}-\mathrm{N}$ & $-, \mathrm{mg} \mathrm{L}^{-1}, \mathrm{mg} \mathrm{L}^{-1}$ & SW & $1 \times 3$ & $\begin{array}{l}\text { Sys4 (inlet, piped } \\
\text { stream) }\end{array}$ & Multiparameter probe & $\begin{array}{l}\text { Nadler pH } \\
\text { electrode, } \\
\text { ion selective } \\
\text { electrodes }\end{array}$ & 1 & LAN & $\mathrm{MN}$ & 2011 \\
\hline Discharge & $\mathrm{Ls}^{-1}$ & SW & 1 & Frau1 (tile drain) & $\begin{array}{l}\text { H-flume, pressure transducer } \\
\text { (water level) }\end{array}$ & $\begin{array}{l}\text { Druck } \\
\text { PTX1830 }\end{array}$ & 1 & LAN & MN & 2011 \\
\hline Discharge (low flows) & $\mathrm{Ls}^{-1}$ & SW & 1 & Frau1 (tile drain) & Tipping bucket (counts) & Reed sensor & 1 & LAN & MN & 2011 \\
\hline Discharge & $\mathrm{Ls}^{-1}$ & SW & 1 & Frau2 (tile drain) & $\begin{array}{l}\text { H-flume, pressure transducer } \\
\text { (water level) }\end{array}$ & OTT PS1 & 1 & LAN & MN & 2011 \\
\hline $\begin{array}{l}\text { Electrical conductivity and } \\
\text { water temperature }\end{array}$ & $\mu \mathrm{S} \mathrm{cm}^{-1},{ }^{\circ} \mathrm{C}$ & SW & $1 \times 2$ & Frau2 (tile drain) & Electric conductivity probe & $\begin{array}{l}\text { WTW } \\
\text { TetraCon }\end{array}$ & 1 & LAN & MN & 2012 \\
\hline $\mathrm{pH}, \mathrm{Cl}, \mathrm{NO}_{3}-\mathrm{N}$ & $-, \mathrm{mg} \mathrm{L}^{-1}, \mathrm{mg} \mathrm{L}^{-1}$ & SW & $1 \times 3$ & Frau2 (tile drain) & Multiparameter probe & $\begin{array}{l}\text { Nadler pH } \\
\text { electrode, ion } \\
\text { selective } \\
\text { electrodes }\end{array}$ & 1 & LAN & MN & 2012 \\
\hline Discharge & $\mathrm{Ls}^{-1}$ & SW & 1 & Sys1 (tile drain) & $\begin{array}{l}\text { H-flume, pressure transducer } \\
\text { (water level) }\end{array}$ & OTT PS1 & 1 & LAN & MN & 2011 \\
\hline Discharge (low flows) & $\mathrm{Ls}^{-1}$ & SW & 1 & Sys1 (tile drain) & $\begin{array}{l}\text { H-flume, Tipping bucket } \\
\text { (counts) }\end{array}$ & Reed sensor & 1 & LAN & MN & 2011 \\
\hline Discharge & $\mathrm{Ls}^{-1}$ & SW & 1 & Sys2 (tile drain) & $\begin{array}{l}\text { H-flume, pressure transducer } \\
\text { (water level) }\end{array}$ & OTT PS1 & 1 & LAN & MN & 2011 \\
\hline $\begin{array}{l}\text { Electrical conductivity and } \\
\text { water temperature }\end{array}$ & $\mu \mathrm{S} \mathrm{cm}^{-1},{ }^{\circ} \mathrm{C}$ & SW & $1 \times 2$ & Sys2 (tile drain) & Electric conductivity probe & $\begin{array}{l}\text { WTW } \\
\text { TetraCon }\end{array}$ & 1 & LAN & MN & 2011 \\
\hline $\mathrm{pH}, \mathrm{Cl}, \mathrm{NO}_{3}-\mathrm{N}$ & $-, \mathrm{mg} \mathrm{L}^{-1}, \mathrm{mg} \mathrm{L}^{-1}$ & SW & $1 \times 3$ & Sys2 (tile drain) & Multiparameter probe & $\begin{array}{l}\text { Nadler } \mathrm{pH} \\
\text { electrode, } \\
\text { ion selective } \\
\text { electrodes }\end{array}$ & 1 & LAN & MN & 2011 \\
\hline Discharge & $\mathrm{Ls}^{-1}$ & SW & 1 & Sys3 (tile drain) & $\begin{array}{l}\text { H-flume, pressure transducer } \\
\text { (water level) }\end{array}$ & $\begin{array}{l}\text { Druck } \\
\text { PTX1830 }\end{array}$ & 1 & LAN & MN & 2011 \\
\hline Discharge (low flows) & $\mathrm{Ls}^{-1}$ & SW & 1 & Sys3 (tile drain) & H-flume, Tipping bucket (counts) & Reed sensor & 1 & LAN & MN & 2011 \\
\hline Discharge & $\mathrm{Ls}^{-1}$ & SW & 1 & E1 (erosion gully) & $\begin{array}{l}\text { H-flume, pressure transducer } \\
\text { (water level) }\end{array}$ & $\begin{array}{l}\text { Druck } \\
\text { PTX1830 }\end{array}$ & 1 & LAN & $\mathrm{MN}$ & 2011 \\
\hline
\end{tabular}


Table B1. Continued.

\begin{tabular}{|c|c|c|c|c|c|c|c|c|c|c|}
\hline Variable & Units & Comp. & $\begin{array}{l}\text { No. of } \\
\text { stations } \times \\
\text { sensors }\end{array}$ & Location & Sensor & Sensor type & $\begin{array}{l}\text { Temporal } \\
\text { resolution } \\
\text { (mins) }\end{array}$ & $\begin{array}{l}\text { Data } \\
\text { connectivity }\end{array}$ & $\begin{array}{l}\text { Main data } \\
\text { storage }\end{array}$ & $\begin{array}{l}\text { Data from } \\
\text { (year) }\end{array}$ \\
\hline Turbidity & $\mathrm{mg} \mathrm{L}^{-1}$ & SW & 1 & E1 (erosion gully) & Turbidity probe & $\begin{array}{l}\text { WTW } \\
\text { ViSolid }\end{array}$ & 1 & LAN & MN & 2011 \\
\hline Discharge & $\mathrm{Ls}^{-1}$ & SW & 1 & E2 (erosion gully) & $\begin{array}{l}\text { H-flume, pressure transducer } \\
\text { (water level) }\end{array}$ & OTT PS1 & 1 & LAN & MN & 2011 \\
\hline Turbidity & $\mathrm{mg} \mathrm{L}^{-1}$ & SW & 1 & E2 (erosion gully) & Turbidity probe & $\begin{array}{l}\text { WTW } \\
\text { ViSolid }\end{array}$ & 1 & LAN & MN & 2011 \\
\hline Discharge & $\mathrm{Ls}^{-1}$ & SW & 1 & Q1 (spring) & $\begin{array}{l}\text { V-notch weir, pressure } \\
\text { transducer (water level) }\end{array}$ & Druck PTX1830 & 1 & LAN & MN & 2011 \\
\hline Discharge & $\mathrm{Ls}^{-1}$ & SW & 1 & K1 (spring) & $\begin{array}{l}\text { V-notch weir, pressure trans- } \\
\text { ducer } \\
\text { (water level) }\end{array}$ & Druck PTX1830 & 1 & LAN & MN & 2011 \\
\hline Discharge & $\mathrm{Ls}^{-1}$ & SW & 1 & $\begin{array}{l}\text { A1 (wetland } \\
\text { runoff) }\end{array}$ & $\begin{array}{l}\text { H-flume, pressure transducer } \\
\text { (water level) }\end{array}$ & OTT PS1 & 1 & LAN & MN & 2011 \\
\hline $\begin{array}{l}\text { Electrical conductivity and } \\
\text { water temperature }\end{array}$ & $\mu \mathrm{S} \mathrm{cm}^{-1},{ }^{\circ} \mathrm{C}$ & SW & $1 \times 2$ & $\begin{array}{l}\text { A1 (wetland } \\
\text { runoff) }\end{array}$ & Electric conductivity probe & $\begin{array}{l}\text { WTW } \\
\text { TetraCon }\end{array}$ & 1 & LAN & MN & 2011 \\
\hline $\mathrm{pH}, \mathrm{Cl}, \mathrm{NO}_{3}-\mathrm{N}$ & $-, \mathrm{mgL}^{-1}, \mathrm{mg} \mathrm{L}^{-1}$ & SW & $1 \times 3$ & $\begin{array}{l}\text { A1 (wetland } \\
\text { runoff) }\end{array}$ & Multiparameter probe & $\begin{array}{l}\text { Nadler } \mathrm{pH} \\
\text { electrode, ion se- } \\
\text { lective electrodes }\end{array}$ & 1 & LAN & MN & 2011 \\
\hline Discharge & $\mathrm{Ls}^{-1}$ & SW & 1 & $\begin{array}{l}\text { A2 (wetland } \\
\text { runoff) }\end{array}$ & $\begin{array}{l}\text { H-flume, pressure transducer } \\
\text { (water level) }\end{array}$ & Druck PTX1830 & 1 & LAN & MN & 2011 \\
\hline Discharge (low flows) & $\mathrm{Ls}^{-1}$ & SW & 1 & $\begin{array}{l}\text { A2 (wetland } \\
\text { runoff) }\end{array}$ & H-flume, tipping bucket (counts) & Reed sensor & 1 & LAN & MN & 2011 \\
\hline Discharge & $\mathrm{Ls}^{-1}$ & SW & 1 & MW & $\begin{array}{l}\text { Thomson weir, stage recorder } \\
\text { (water level) }\end{array}$ & $\begin{array}{l}\text { Ott stage } \\
\text { recorder }\end{array}$ & 1 & $\mathrm{M}$ & IKT & $1945-2002$ \\
\hline Discharge and water temperature & $\mathrm{Ls} \mathrm{s}^{-1},{ }^{\circ} \mathrm{C}$ & SW & 1 & MW & $\begin{array}{l}\text { H-flume, pressure transducer } \\
\text { (water level) }\end{array}$ & Ott PS1 & 1 & $\mathrm{M}$ & MN & $2002-2009$ \\
\hline Discharge and water temperature & $\mathrm{Ls}^{-1},{ }^{\circ} \mathrm{C}$ & SW & 1 & MW & $\begin{array}{l}\text { H-flume, pressure transducer } \\
\text { (water level) }\end{array}$ & Druck PTX1830 & 1 & LAN & MN & 2009 \\
\hline Discharge & $\mathrm{Ls}^{-1}$ & SW & 1 & MW & $\begin{array}{l}\text { H-flume, Ultrasonic probe (water } \\
\text { level) }\end{array}$ & Endress/Hauser & 1 & LAN & MN & 2010 \\
\hline $\begin{array}{l}\text { Electrical conductivity and water } \\
\text { temperature }\end{array}$ & $\mu \mathrm{S} \mathrm{cm}{ }^{-1},{ }^{\circ} \mathrm{C}$ & SW & $1 \times 2$ & MW & Electric conductivity probe & $\begin{array}{l}\text { WTW } \\
\text { TetraCon }\end{array}$ & 1 & LAN & MN & 2009 \\
\hline Turbidity & $\mathrm{mg} \mathrm{L}^{-1}$ & SW & 1 & MW & Turbidity probe & $\begin{array}{l}\text { WTW } \\
\text { ViSolid }\end{array}$ & 1 & LAN & MN & 2009 \\
\hline Turbidity & $\mathrm{mg} \mathrm{L}^{-1}$ & SW & 1 & MW & Turbidity probe & $\begin{array}{l}\text { Hach Lange } \\
\text { SOLITAX ts-line } \\
\text { sc }\end{array}$ & 1 & LAN & MN & only 2010 \\
\hline $\mathrm{pH}, \mathrm{Cl}, \mathrm{NO}_{3}-\mathrm{N}$ & $-, \mathrm{mg} \mathrm{L}^{-1}, \mathrm{mg} \mathrm{L}^{-1}$ & SW & $1 \times 3$ & MW & Multiparameter probe & $\begin{array}{l}\text { Nadler } \mathrm{pH} \\
\text { electrode, ion se- } \\
\text { lective electrodes }\end{array}$ & 1 & LAN & MN & 2011 \\
\hline beta-D-glucuronidase activity & $\mathrm{pmol} / \mathrm{min} / 100 \mathrm{ml}$ & SW & $1 \times 2$ & MW & Fluorescence analyser & $\begin{array}{l}\text { Photometric cu- } \\
\text { vette (Coliguard } \\
0025,0035)\end{array}$ & 180 & $\mathrm{P}$ & $\mathrm{TU}$ & 2011,2012 \\
\hline beta-D-glucuronidase activity & $\mathrm{mMFU} / 100 \mathrm{ml}$ & SW & $1 \times 2$ & MW & Fluorescence analyser & $\begin{array}{ll}\text { Photometric } & \text { cu- } \\
\text { vette } & \\
\text { (Coliminder } & \text { A, } \\
\text { B) } & \end{array}$ & 60 & $\mathrm{P}$ & VWM & 2014 \\
\hline $\begin{array}{l}\text { TSS, } \mathrm{NO}_{3}-\mathrm{N}, \mathrm{COD}, \mathrm{BOD}, \mathrm{TOC}, \\
\text { DOC, turbidity, UV254 }\end{array}$ & $\begin{array}{l}\mathrm{mg} \mathrm{L}^{-1}, \quad \mathrm{FNU} \\
\mathrm{Abs} \mathrm{m}^{-1}\end{array}$ & SW & $1 \times 2$ & MW & Spectrolyser & $\begin{array}{l}\text { s::can } \\
\text { spectrolyser UV- } \\
\text { Vis, } \quad 15 / 35 \mathrm{~mm} \\
\text { pathlength, } 220- \\
700 \mathrm{~nm} \text { range }\end{array}$ & 10 & $\mathrm{M}$ & $\mathrm{TU}$ & 2013 \\
\hline Visual images of flume & - & SW & 1 & MW & Camera & Axis P5512-E & 1 & LAN & HP & 2014 \\
\hline Soil heat flux & $\mathrm{Wm}^{-2}$ & Soil & $1 \times 2$ & ws & Soil heat flux $-30 \mathrm{~cm}$ & $\begin{array}{l}\text { Huskeflux } \\
\text { HFP01SC }\end{array}$ & $30 ; 1$ & LAN & $\mathrm{HP}$ & 2012 \\
\hline Soil temperature & ${ }^{\circ} \mathrm{C}$ & Soil & $2 \times 5$ & WS & $\begin{array}{l}\text { Soil temperature at }-5 \mathrm{~cm}, \\
-10 \mathrm{~cm},-15 \mathrm{~cm},-20 \mathrm{~cm}, \\
-30 \mathrm{~cm}\end{array}$ & PT107 & $30 ; 1$ & LAN & HP & 2012 \\
\hline Soil moisture, soil temperature & $\begin{array}{l}\% \text { volumetric soil } \\
\text { water content, }{ }^{\circ} \mathrm{C}\end{array}$ & Soil & $\begin{array}{l}18 \times 4 \\
2 \times 5\end{array}$ & Catchment & $\begin{array}{l}\text { Permanent soil moisture sensors } \\
-5,-10,-20,-50,(2-100 \mathrm{~cm})\end{array}$ & $\begin{array}{l}\text { Spade-TDT } \\
\text { (Jülich) }\end{array}$ & 30 & LAN & Soil & 2013 \\
\hline Soil moisture, soil temperature & $\begin{array}{l}\% \text { volumetric soil } \\
\text { water content, }{ }^{\circ} \mathrm{C}\end{array}$ & Soil & $11 \times 4$ & Catchment & $\begin{array}{l}\text { Temporary soil moisture sensors } \\
-5,-10,-20,-50 \mathrm{~cm}\end{array}$ & $\begin{array}{l}\text { Spade-TDT } \\
\text { (Jülich) }\end{array}$ & 30 & LAN & Soil & 2013 \\
\hline Soil moisture & $\begin{array}{l}\% \text { volumetric soil } \\
\text { water content }\end{array}$ & Soil & 1 & Catchment & $\begin{array}{l}\text { Cosmic ray soil moisture neutron } \\
\text { probe }(680 \mathrm{~m} \text { footprint, } 12-76 \mathrm{~cm} \\
\text { depth) }\end{array}$ & CRS $1000 / \mathrm{B}$ & 60 & $\mathrm{~s}$ & Cosmos & 2013 \\
\hline $\begin{array}{l}\text { Groundwater level and tempera- } \\
\text { ture }\end{array}$ & $\mathrm{cm} \mathrm{H}_{2} \mathrm{O},{ }^{\circ} \mathrm{C}$ & GW & 23 & $\begin{array}{l}\text { Catchment near } \\
\text { stream (BP01, } \\
\mathrm{BP} 02, \ldots)\end{array}$ & Groundwater data loggers & SWS Mini-Diver & $5-30$ & $\mathrm{M}$ & IKT & 2011 \\
\hline $\begin{array}{l}\text { Atmospheric pressure and tem- } \\
\text { perature }\end{array}$ & $\mathrm{cm} \mathrm{H}_{2} \mathrm{O},{ }^{\circ} \mathrm{C}$ & $\mathrm{A}$ & 2 & $\begin{array}{l}\text { near stream } \\
\text { (Baro1, Baro2) }\end{array}$ & Groundwater data loggers & SWS Baro-Diver & $5-30$ & M & IKT & 2011 \\
\hline
\end{tabular}


Table B2. Laboratory analyses from samples taken in the HOAL. Main data storage: IKT $=$ IKT server (plain file system), TU $=$ TU server, UFZ $=$ UFZ server. * Note: physical and chemical analysis (potentiometric, conductometric, filtering, ion chromatographic, photometric, spectrometric).

\begin{tabular}{|c|c|c|c|c|c|c|c|c|c|}
\hline Variable & Units & Comp. & $\begin{array}{l}\text { No. of } \\
\text { stations } \times \\
\text { sensors }\end{array}$ & Location & Sampling & Analysis & $\begin{array}{l}\text { Temporal } \\
\text { resolution }\end{array}$ & $\begin{array}{l}\text { Main } \\
\text { data } \\
\text { storage }\end{array}$ & $\begin{array}{l}\text { Data } \\
\text { from } \\
\text { (year) }\end{array}$ \\
\hline $\begin{array}{l}\mathrm{pH}, \mathrm{EC}, \mathrm{SSC}, \mathrm{Cl}, \mathrm{NO}_{3}, \\
\mathrm{NH}_{4}, \mathrm{P}\end{array}$ & $\begin{array}{l}-, \mu \mathrm{Scm}^{-1} \\
\mathrm{mg} \mathrm{L}^{-1}\end{array}$ & SW & 2 & MW & $\begin{array}{l}\text { Autosampler Isco } \\
6712\end{array}$ & $\begin{array}{l}\text { Physical and chemical } \\
\text { analysis* (IKT Lab) }\end{array}$ & Within event & IKT & 2009 \\
\hline $\begin{array}{l}\mathrm{pH}, \mathrm{EC}, \mathrm{SSC}, \mathrm{Cl}, \mathrm{NO}_{3}, \\
\mathrm{NH}_{4}, \mathrm{P}\end{array}$ & $\begin{array}{l}-, \mu \mathrm{Scm}^{-1} \\
\mathrm{mg} \mathrm{L}^{-1}\end{array}$ & SW & - & MW & Grab samples & $\begin{array}{l}\text { Physical and chemical } \\
\text { analysis* (IKT Lab) }\end{array}$ & Weekly & IKT & 2010 \\
\hline TOC & $\mathrm{mg} \mathrm{L}^{-1}$ & SW & 1 & MW & Grab samples & $\begin{array}{l}\text { Thermal catalytic oxidation } \\
\text { (IKT Lab) }\end{array}$ & $\begin{array}{l}\text { Within event } \\
\text { or weekly }\end{array}$ & IKT & 2013 \\
\hline $\begin{array}{l}\mathrm{pH}, \mathrm{EC}, \mathrm{SSC}, \mathrm{Cl}, \mathrm{NO}_{3}, \\
\mathrm{NH}_{4}, \mathrm{P}\end{array}$ & $\begin{array}{l}-, \mu \mathrm{Scm}^{-1} \\
\mathrm{mg} \mathrm{L}^{-1}\end{array}$ & SW & $4 \times 1$ & $\begin{array}{l}\text { E1, E2 (erosion } \\
\text { gullies), Frau2 } \\
\text { (tile drain), } \\
\text { Sys4 (inlet, } \\
\text { piped stream) }\end{array}$ & $\begin{array}{l}\text { Autosampler Isco } \\
6712\end{array}$ & $\begin{array}{l}\text { Physical and chemical } \\
\text { analysis* (IKT Lab) }\end{array}$ & Within event & IKT & $\begin{array}{l}2011 \\
\text { or } \\
2013\end{array}$ \\
\hline $\begin{array}{l}\text { DOC, TOC, PO4-P, } \\
\mathrm{NH}_{4}-\mathrm{N}, \quad \mathrm{NO}_{3}-\mathrm{N}, \quad \mathrm{TP}, \\
\mathrm{TN}, \mathrm{SS}, \mathrm{HCO}_{3}, \mathrm{Cl}, \mathrm{SO}_{4}, \\
\mathrm{pH}, \mathrm{EC}, \mathrm{Na}, \mathrm{K}, \mathrm{Ca}, \mathrm{Mg}\end{array}$ & $\begin{array}{l}-, \mu \mathrm{Scm}^{-1} \\
\mathrm{mg} \mathrm{L}^{-1}\end{array}$ & SW & - & All tributaries & Grab samples & $\begin{array}{l}\text { Physical and chemical } \\
\text { analysis* (IKT Lab) }\end{array}$ & Monthly & IKT & 2010 \\
\hline Precipitation ${ }^{18} \mathrm{O},{ }^{2} \mathrm{H}$ & & A & 1 & $\begin{array}{l}\text { Close to catchment } \\
\text { (IKT) }\end{array}$ & $\begin{array}{l}\text { Autosampler } \\
\text { Manning S-4040, } \\
\text { adapted }\end{array}$ & $\begin{array}{l}\text { Laser spectroscopy (Picarro } \\
\text { L1115-i, AIT Tulln }\end{array}$ & Event-based & IKT & 2009 \\
\hline Discharge ${ }^{18} \mathrm{O},{ }^{2} \mathrm{H}$ & & SW & - & MW, all tributaries & Grab samples & $\begin{array}{l}\text { Laser spectroscopy (Picarro } \\
\text { L1115-i, AIT Tulln }\end{array}$ & $\begin{array}{l}\text { Within event } \\
\text { or monthly }\end{array}$ & IKT & 2009 \\
\hline Discharge ${ }^{3} \mathrm{H}$ & & SW & - & Q1 & Grab samples & $\begin{array}{l}\text { Laser spectroscopy (Picarro } \\
\text { L1115-i, AIT Tulln }\end{array}$ & Monthly & IKT & 2013 \\
\hline Precipitation ${ }^{18} \mathrm{O},{ }^{15} \mathrm{~N}$ & & A & - & $\begin{array}{l}\text { Close to catchment } \\
\text { (IKT) }\end{array}$ & $\begin{array}{l}\text { Autosampler } \\
\text { Manning S-4040, } \\
\text { adapted }\end{array}$ & $\begin{array}{l}\text { Mass spectrometry } \\
\text { (DELTA V Plus + } \\
\text { GasBench II, Thermo } \\
\text { Scientific; L1102-I, } \\
\text { Picarro) }\end{array}$ & Event based & UFZ & 2013 \\
\hline Discharge ${ }^{18} \mathrm{O},{ }^{15} \mathrm{~N}$ & & SW & - & All tributaries & Grab samples & $\begin{array}{l}\text { Mass spectrometry } \\
\text { (DELTA V Plus + } \\
\text { GasBench II, Thermo } \\
\text { Scientific; L1102-I, } \\
\text { Picarro) }\end{array}$ & Monthly & UFZ & 2013 \\
\hline E. coli, coliforms & MPN/100 ml & SW & - & MW, partly tributaries & Grab samples & $\begin{array}{l}\text { Colilert-18 Quanti-Tray } \\
\text { (IKT Lab) }\end{array}$ & Monthly & $\mathrm{TU}$ & 2012 \\
\hline $\begin{array}{l}\text { E. coli, aerobic spores, } \\
\text { clostridium perfringens } \\
\text { spores, total cell count }\end{array}$ & $\mathrm{CFU} / 100 \mathrm{ml}$ & SW & - & MW & Grab samples & $\begin{array}{l}\text { TBX Agar ISO 16649-1 } \\
\text { (Med Univ Vienna) }\end{array}$ & Monthly & $\mathrm{TU}$ & 2012 \\
\hline
\end{tabular}


Appendix C: Photos of stream gauges
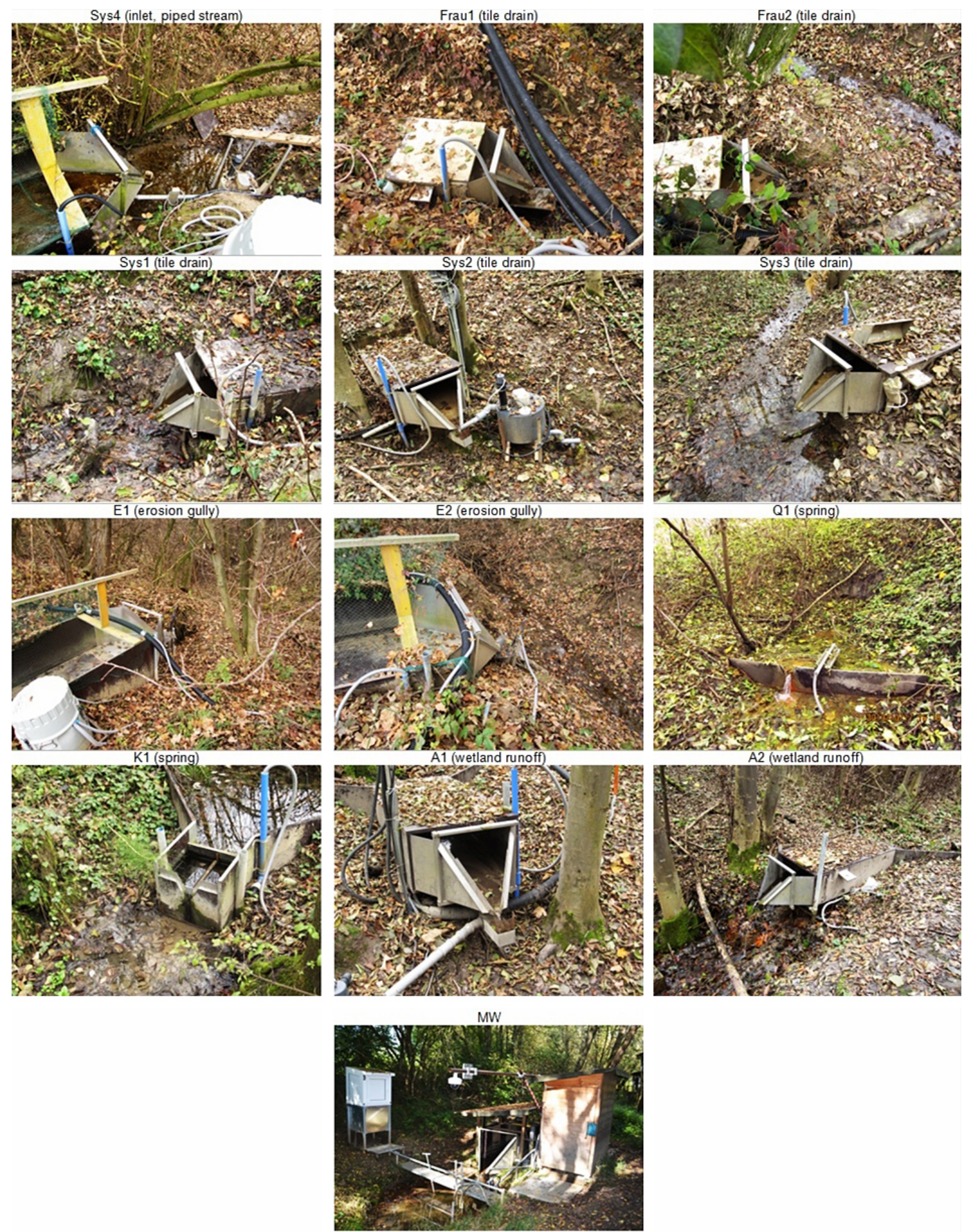

Figure C1. Photos of the 13 stream gauges in the HOAL. 
Acknowledgements. The authors would like to thank the Austrian Science Funds (Doctoral Programme on Water Resource Systems, W 1219-N22), the TU Wien (three innovative projects, Lion equipment pool, startup funds, ERC FloodChange commitment, staff base funding) as well as the Federal Agency for Water Management for financial support. We would also like to thank Vienna Water Monitoring (VWM) for the cooperation in the ColiMinder 2014-2015 project funded by the Austrian Research Promotion Agency. Financial support has also been provided by the private Land is Water association.

Edited by: M. Sivapalan

\section{References}

Anderson, S. P., Bales, R. C., and Duffy, C. J.: Critical zone observatories: Building a network to advance interdisciplinary study of Earth surface processes, Mineralogical Magazine, 72, 7-10, 2008.

Blöschl, G. and Zehe, E.: On hydrological predictability, Invited commentary, Hydrol. Process., 19, 3923-3929, 2005.

Blöschl, G., Gutknecht, D., and Kirnbauer, R.: Distributed snowmelt simulations in an Alpine catchment. 2. Parameter study and model predictions, Water Resour. Res., 27, 3181-3188, 1991.

Blöschl, G., Carr, G., Bucher, C., Farnleitner, A. H., Rechberger, H., Wagner, W., and Zessner, M.: Promoting interdisciplinary education - the Vienna Doctoral Programme on Water Resource Systems. Hydrology and Earth System Sciences, 16, 457-472, doi:10.5194/hess-16-457-2012, 2012.

Blöschl, G., Bárdossy, A., Koutsoyiannis, D., Kundzewicz, Z. W., Littlewood, I., Montanari, A., and Savenije, H.: Joint Editorial "On the future of journal publications in hydrology", Hydrol. Earth Syst. Sci., 18, 2433-2435, doi:10.5194/hess-18-24332014, 2014.

Blöschl, G., Thybo, H., Savenije, H., and Lovejoy, S.: A Voyage, in: A Voyage Through Scales - The Earth System in Space and Time, edited by: Blöschl, G., Thybo, H., and Savenije, H., Edition Lammerhuber, Vienna, 13-18, 2015.

Blümel, F. and Klaghofer, E.: Bericht über den Stand der Oberflächenabflußmessungen im Jahr 1976. Sonderdr. aus: Sitzungsberichte der Österr. Akademie der Wissenschaften, Math.naturw. Kl., Abt. I, 186. Bd., 1. bis 3. Heft, Wien, 1977.

Bogena, H. R., Herbst, M., Huisman, J. A., Rosenbaum, U., Weuthen, A., and Vereecken, H.: Potential of wireless sensor networks for measuring soil water content variability, Vadose Z. J. 9, 1002-1013, 2010.

Brown, A. E., Zhang, L., McMahon, T. A., Western, A. W., and Vertessy, R. A.: A review of paired catchment studies for determining changes in water yield resulting from alterations in vegetation, J. Hydrol., 310, 28-61, 2005.

Carr, G., Loucks, D. P., Blanch, A. R., Blaschke, A. P., Brouwer, R., Bucher, C., Farnleitner, A. H., Fürnkranz-Prskawetz, A., Morgenroth, E., Parajka, J., Pfeifer, N., Rechberger, H., Wagner, W. W., Zessner, M., and Blöschl, G.: Evaluating multi-disciplinary collaboration in a doctoral programme on water resource systems, to be submitted, 2015 .
Chamberlin, T. C.: The method of multiple working hypotheses, Science, 15, 754-759, doi:10.1126/science.148.3671.754, 1965.

Eder, A., Strauss, P., Krueger, T., and Quinton, J. N.: Comparative calculation of suspended sediment loads with respect to hysteresis effects (in the Petzenkirchen catchment, Austria), J. Hydrol. 389, 168-176, 2010.

Eder, A., Exner-Kittridge, M., Strauss, P., and Blöschl G.: Resuspension of bed sediment in a small stream - results from two flushing experiments, Hydrol. Earth Syst. Sci. 18, 1043-1052, doi:10.5194/hess-18-1043-2014, 2014.

Elliott, K. J. and Vose, J. M.: The contribution of the Coweeta Hydrologic Laboratory to developing an understanding of long-term (1934-2008) changes in managed and unmanaged forests, Forest Ecol. Manage., 261, 900-910, 2011.

Exner-Kittridge, M., Niederreiter, R., Eder, A., and Zessner, M.: A simple and flexible field tested device for housing water monitoring sensors at point discharges, Water Sci. Technol., 67, 10261033, 2013.

Exner-Kittridge, M., Salinas, J. L., and Zessner, M.: An evaluation of analytical stream to groundwater exchange models: a comparison of gross exchanges based on different spatial flow distribution assumptions, Hydrol. Earth Syst. Sci., 18, 2715-2734, doi:10.5194/hess-18-2715-2014, 2014.

Exner-Kittridge, M., Blöschl, G., Eder, A., Strauss, P., and Zessner, M.: Source contribution dynamics of runoff events in a headwater agricultural catchment, submitted to Water Resour. Res., 2016.

FAO (Food and Agriculture Organization of the United Nations): Crop evapotranspiration: guidelines for computing crop water requirements, no. 56 in FAO irrigation and drainage paper, Rome, 1998.

Farnleitner, A. H., Hocke, L., Beiwl, C., Kavka, G. G., Zechmeister, T., Kirschner, A. K. T., and Mach, L. R.: Rapid enzymatic detection of Escherichia coli contamination in polluted river water, Lett. Appl. Microbiol., 33, 246-250, 2001.

Farnleitner, A. H., Hocke, L., Beiwl, C., Kavka, G. G., and Mach, R. L.: Hydrolysis of 4-methylumbelliferyl- $\beta$-D-glucuronide in differing sample fractions of river waters and its implication for the detection of fecal pollution, Water Res., 36, 975-981, 2002.

Farnleitner, A. H., Reischer, G. H., Stadler, H., Kollanur, D., Sommer, R., Zerobin, W., Blöschl, G., Barrella, K. M., Truesdale, J. A., Casarez, E. A., and Di Giovanni, G. D.: Microbial Source Tracking: Methods, Applications and Case Studies. Chapter 18 - Agricultural and Rural Watersheds, edited by: Hagedorn, C., Haarwood, J., and Blanch A., Springer, New York, 399-432, 2011.

Flores Orozco, A., Williams, K. H., Long, P. E., Hubbard, S. S., and Kemna, A.: Using complex resistivity imaging to infer biogeochemical processes associated with bioremediation of a uranium-contaminated aquifer, J. Geophys. Res., 116, G03001, doi:10.1029/2010JG001591, 2011.

Flores Orozco, A., Williams, H. K., and Kemna, A.: Timelapse spectral induced polarization imaging of stimulated uranium bioremediation, Near Surf. Geophys., 11, 531-544, doi:10.3997/1873-0604.2013020, 2013.

Flores Orozco, A., Velimirovic, M., Tosco, T., Kemna, A., Sapion, H., Klaas, N., Sethi, R., and Leen, B.: Monitoring the injection of microscale zero-valent iron particles for groundwater remediation by means of complex electrical conductivity imaging, Envi- 
ron. Sci. Technol., 49, 5593-5600, doi:10.1021/acs.est.5b00208, 2015.

Grayson, R. B. and Western, A. W.: Towards areal estimation of soil water content from point measurements: time and space stability of mean response, J. Hydrol., 207, 68-82, 1998.

Grayson, R. B., Western, A. W., Chiew, F. H., and Blöschl, G.: Preferred states in spatial soil moisture patterns: Local and nonlocal controls, Water Resour. Res., 33, 2897-2908, 1997.

Grayson, R., Blöschl, G., Western, A., and McMahon, T.: Advances in the use of observed spatial patterns of catchment hydrological response, Adv. Water Resour., 25, 1313-1334, 2002.

Holko, L., Holzmann, L., de Lima, M. I. P., and de Lima, J. L. M. P.: Hydrological research in small catchments - an approach to improve knowledge on hydrological processes and global change impacts, J. Hydrol. Hydromech., 63, 181-182, 2015.

Holländer, H. M., Blume, T., Bormann, H., Buytaert, W., Chirico, G. B., Exbrayat, J.-F., Gustafsson, D., Hölzel, H., Kraft, P., Stamm, C., Stoll, S., Blöschl, G., and Flühler, H.: Comparative predictions of discharge from an artificial catchment (Chicken Creek) using sparse data, Hydrology and Earth System Sciences, 13, 2069-2094, 2009.

Holländer, H. M., Bormann, H., Blume, T., Buytaert, W., Chirico, G. B., Exbrayat, J.-F., Gustafsson, D., Hölzel, H., Krauße, T., Kraft, P., Stoll, S., Blöschl, G., and Flühler, H.: Impact of modellers' decisions on hydrological a priori predictions, Hydrol. Earth Syst. Sci., 18, 2065-2085, doi:10.5194/hess-18-20652014, 2014.

Hopp, L., Harman, C., Desilets, S. L. E., Graham, C. B., McDonnell, J. J., and Troch, P. A.: Hillslope hydrology under glass: confronting fundamental questions of soil-water-biota coevolution at Biosphere 2, Hydrol. Earth Syst. Sci., 13, 21052118, doi:10.5194/hess-13-2105-2009, 2009.

Horvath, Z., Waser, J., Perdigao, R. A. P., Konev, A., and Blöschl, G.: A two-dimensional numerical scheme of dry/wet fronts for the Saint-Venant system of shallow water equations, Int. J. Num. Meth. Fluids, 77, 159-182, 2015.

Kazemi Amiri, A. and Bucher, C.: Derivation of a new parametric impulse response matrix utilized for nodal wind load identification by response measurement, J. Sound Vibr., 344, 101-113, 2015.

Kirby, C., Newson, M., and Gilman, K. (eds.): Plynlimon research: the first two decades - IH Report 109, www.ceh.ac.uk/products/ publications/Plynlimonresearchthefirsttwodecades.html, (last access 11 July 2015) 1991.

Kirnbauer, R., Blöschl, G., Haas, P., Müller, G., and Merz, B.: Identifying space-time patterns of runoff generation - A case study from the Löhnersbach catchment, Austrian Alps, in: Global Change and Mountain Regions, edited by: Huber, U., Bugmann, H., and Reasoner, M., Springer, Series on Advances in Global Change Research, 23, 309-320, 2005.

Knorr-Cetina, K. D.: The manufacture of knowledge: An essay on the constructivist and contextual nature of science, Elsevier, 204 pp., 2013.

Kovacs, A., Honti, M., Zessner, M., Eder, A., Clement, A., and Blöschl, G.: Identification of phosphorus emission hotspots in agricultural catchments, Sci. Total Environ., 433, 74-88, 2012.

Leibundgut, Ch., Blöschl, G., Borchardt, D., Bundi, U., Hansjürgens, B., Merz, B., and Nobilis, F.: Nachhaltige Wassernutzung in der Schweiz. Gesamtsynthese: NFP61 weist Wege in die
Zukunft (Sustainable water management in Switzerland: NRP 61 shows the way ahead), Aqua Gas, 11, 10-16, 2014.

Lin, H. and Hopmans, J. W.: Interdisciplinary sciences in a global network of critical zone observatories, Vadose Z. J., 10, 781-785, 2011.

Mauder, M. and Foken, T.: Documentation and instruction manual of the eddy covariance software package TK3. Universität Bayreuth, Abt. Mikrometeorologie, Arbeitsergebnisse, 60 pp., 2011.

Merz, R. and Blöschl, G.: Flood frequency hydrology: 1. Temporal, spatial, and causal expansion of information, Water Resour. Res., 44, W08432, doi:10.1029/2007WR006744, 2008.

Parajka, J., Haas, P., Kirnbauer, R., Jansa, J., and Blöschl, G.: Potential of time-lapse photography of snow for hydrological purposes at the small catchment scale, Hydrol. Process., 26, 3327-3337, 2012.

Plate, E. and Zehe, E.: Hydrologie und Stoffdynamik kleiner Einzugsgebiete- Prozesse und Modelle, Schweizerbart, Stuttgart 366 pp., 2008.

Reischer, G. H., Kollanur, D., Vierheilig, J., Wehrspaun, C., Mach, R., Stadler, H., Sommer, R., and Farnleitner, A. H.: A hypothesisdriven approach for the identification of fecal pollution sources in water resources, Environ. Sci. Technol., 45, 4038-4045, 2011.

Robinson, M., Rodda, J. C., and Sutcliffe, J. V.: Long-term environmental monitoring in the UK: origins and achievements of the Plynlimon catchment study, Transactions of the Institute of British Geographers, 38, 451-463, 2013.

Ryzinska-Paier, G., Lendenfeld, T., Correa, K., Stadler, P., Blaschke, A. P., Mach, R. L., Stadler, H., Kirschner, A. K. T., and Farnleitner, A. H.: A sensitive and robust method for automated on-line monitoring of enzymatic activities in water and water resources, Water Sci. Technol., 69, 1349-1358, 2014.

Schilling, C., Behrendt, H., Blaschke, A., Danielescu, S., Dimova, G., Gabriel, O., Heinecke, U., Kovacs, A., Lampert, C., Postolache, C., Schreiber, H., Strauss, P., and Zessner, M.: Lessons learned from investigations on case study level for modelling of nutrient emissions in the Danube Basin, Water Sci. Technol., 51, 183-191, 2005.

Schumann S., Schmalz, B., Meesenburg, H., and Schröder, U.: Status and Perspectives of Hydrology in Small Basins. IHP/HWRPBerichte Heft 10, German Federal Institute of Hydrology, Koblenz, 69 pp., 2010.

Sivapalan, M.: The secret to "doing better hydrological science": change the question!, Hydrol. Process., 23, 1391-1396, 2009.

Srinivasan, V., Thompson, S., Madhyastha, K., Penny, G., Jeremiah, K., and Lele, S.: Why is the Arkavathy River drying? A multiplehypothesis approach in a data-scarce region, Hydrol. Earth Syst. Sci., 19, 1905-1917, doi:10.5194/hess-19-1905-2015, 2015.

Stadler, P., Blöschl, G., Vogl, W., Koschelnik, J., Epp, M., Lackner, M., Oismüller, M., Kumpan, M., Nemeth, L., Strauss, P., Sommer, R., Ryzinska-Paier, G., Farnleitner, A. H., and Zessner, M.: Real-time monitoring of beta-D-glucuronidase activity in sediment laden streams: A comparison of instruments, submitted to Environ. Sci. Technol., 2016.

Strauss, P. and Klaghofer, E.: Soil Erosion in Europe: 1.17 Austria, edited by: Boardman J. and Poesen, J., Soil Erosion in Europe, John Wiley, 205-212, 2006.

Strauss, P., Leone, A., Ripa, M. N., Turpin, N., Lescot, J. M., and Laplana, R.: Using critical source areas for targeting cost- 
effective best management practices to mitigate phosphorus and sediment transfer at the watershed scale, Soil Use Manage., 23, 144-153, 2007.

Swank, W. T. and Crossley Jr., D. A.: Forest Hydrology and Ecology at Coweeta, Springer, 469 pp., 1988.

Turpin, N., Laplana, R., Strauss, P., Kaljonen, M., Zahm, F., and Bégué, V.: Assessing the cost, effectiveness and acceptability of best management farming practices: a pluri-disciplinary approach. International journal of agricultural resources, governance and ecology, 5, 272-288, 2006.

Western, A. W., Blöschl, G., and Grayson, R. B.: How well do indicator variograms capture the spatial connectivity of soil moisture?, Hydrol. Process., 12, 1851-1868, 1998.

Western, A. W., Grayson, R. B., Blöschl, G., Willgoose, G. R., and McMahon, T. A.: Observed spatial organisation of soil moisture and its relation to terrain indices, Water Resour. Res., 35, 797$810,1999$.

Western, A. W., Blöschl, G., and Grayson, R. B.: Towards capturing hydrologically significant connectivity in spatial patterns, Water Resour. Res., 37, 83-97, 2001.

Yeshaneh E., Eder, A., and Blöschl, G.: Effects of conservation measures on soil loss in the Koga catchment, Northwestern Ethiopia, Land Degr. Develop., accepted, 2015.
Zacharias, S., Bogena, H., Samaniego, L., Mauder, M., Fuß, R., Pütz, T., Frenzel, M., Schwank, M., Baessler, C., ButterbachBahl, K., Bens, O., Borg, E., Brauer, A., Dietrich, P., Hajnsek, I., Helle, G., Kiese, R., Kunstmann, H., Klotz, S., Munch, J. C., Papen, H., Priesack, E., Schmid, H. P., Steinbrecher, R., Rosenbaum, U., Teutsch, G., Vereecken, H.: A network of terrestrial environmental observatories in Germany, Vadose Z. J., 10, 955 973, 10.2136/vzj2010.0139, 2011.

Zehe, E. and Blöschl, G.: Predictability of hydrologic response at the plot and catchment scales: Role of initial conditions, Water Resour. Res., 40, W10202, doi:10.1029/2003WR002869, 2004.

Zehe, E., Elsenbeer, H., Lindenmaier, F., Schulz, K., and Blöschl, G.: Patterns of predictability in hydrological threshold systems, Water Resour. Res., 43, W07434, 10.1029/2006WR005589, 2007.

Zehe, E., Maurer, T., Ihringer, J., and Plate, E.: Modeling water flow and mass transport in a loess catchment, Phys. Chem. Earth, 6, 487-507, 2001.

Zessner, M., Postolache, C., Clement, A., Kovacs, A., and Strauss, P.: Considerations on the influence of extreme events on the phosphorus transport from river catchments to the sea, Water Sci. Technol., 51, 193-204, 2005. 